\title{
EL NUEVO DERECHO INTERNACIONAL DE LA ENERGÍA A TRAVÉS DEL ESTUDIO DE SUS FUENTES Y EL ORDENAMIENTO DEL MERCADO MUNDIAL DEL PETRÓLEO EN UN CONTEXTO GEOPOLÍTICO-ESPECULATIVO*
}

\author{
Juan Carlos VELÁZQUEZ ELIZARRARÁS**
}

RESUMEN: El autor afirma que a medida que se ha incrementado la importancia del petróleo como principal fuente de energía en el planeta, revolucionando la dinámica política y las negociaciones para su comercialización, se intensifica la necesidad de estudiar, aplicar y consolidar un nuevo derecho internacional de la energía.

ABSTRACT: The author affirms that as the importance of the oil as a main source of energy has been increasing, there has been a grown in the need of studying, applying and consolidating a new International Law of the Energy.

RÉSUMÉ: L'auteur fait l'affirmation que tant que l'importance du essence comment source principal de énergie dans le planète est augmente, en révolutionnant la dynamique politique et la négociation pour ça commercialisation. Il est nécessaire de étudier, appliquer et consolider un nouveau Droit International de l'Energie.

* Artículo recibido el 31 de julio de 2008 y aceptado para su publicación el 7 de agosto de 2008.

** Doctor en ciencias políticas y sociales, y en relaciones internacionales, por la Facultad de Ciencias Políticas y Sociales de la UNAM; posdoctorante en derecho internacional privado por la Universidad Complutense de Madrid; profesor titular de carrera en la Facultad de Ciencias Políticas y Sociales, en el posgrado de la Facultad de Derecho de la UNAM y de la Universidad Anáhuac del Sur; investigador nacional en el SNI. 
SUMARIO: I. Introducción. II. Premisa central. III. El derecho internacional de la energía y el mercado mundial del petróleo. IV. Reflexiones finales.

\section{INTRODUCCIÓN}

Al igual que como ocurrió en los años sesenta con la creación de la OPEP, en 1973, cuando eclosionó la denominada "guerra del petróleo" con la subsecuente creación de la Agencia Internacional de Energía (AIE) de la OCDE, o como sucedió en los ochenta con las crisis de escasez por los conflictos regionales en Oriente Medio, el norte de África y en Asia, y las rupturas políticas por la construcción de Gasoducto Eurosiberiano (el más grande del mundo) todavía en épocas de Guerra Fría, o aun en los noventa con la irrupción de nuevos productores contribuyentes a la oferta petrolera planetaria y con la revitalización del mercado negro de la energía fósil; hoy, de nueva cuenta, en estos momentos convulsos de inusitados repuntes de los precios del oro negro y de otros energéticos no renovables que comienzan a visualizarse en 2004 y que alcanzan su clímax en pleno 2008, surge el gran debate en todos los ámbitos del pensamiento y el quehacer humanos en torno a los nuevos retos y desarrollos del derecho internacional de la energía (DIEn), y a los problemas de la regulación eficaz de un mercado petrolero mundial caracterizado, como nunca antes, por el desorden y la especulación.

Igualmente la atención del mundo se centra en los temas capitales como la degradación del medio ambiente, la agotabilidad irreversible de los recursos finitos, la errática transición a la era de las fuentes alternativas de energía y la puesta en marcha de reformas estructurales indicativas y de políticas energéticas, tanto integrales como coyunturales, en países consumidores y productores de petróleo. Este es el caso de México que - no hay que olvidarlo - siendo importador neto de hidrocarburos en 1974, llegó a ubicarse sólo ocho años después, en 1982, como el cuarto productor mundial reconocido; empero, comenzando, en ese momento, el camino hacia su declinación hasta los niveles que en nuestros días están causando verdadera alarma y preocupación en todos los sectores de la sociedad.

También en estos tiempos se ha venido desarrollando otra gran discusión nacional en torno a la reforma energética y los mecanismos regulatorios y comerciales del derecho internacional energético aplicables en 
México, destacando las ediciones promovidas por la UNAM donde, hasta el momento, las deliberaciones han sido políticas y académicas a nivel de técnicos y especialistas, pero gracias a las manifestaciones sociales ahora se ha podido tener un debate de mayor envergadura, que involucra a los sectores académico en su amplio espectro, político, social y cultural. ${ }^{1}$

De esta suerte, disertar y debatir abiertamente acerca del actual estado de avance y aplicación del derecho internacional energético, del comportamiento caótico del mercado mundial del petróleo que impacta la comercialización estratégica de todas las variedades de hidrocarburos, poniendo énfasis en las viabilidades y consecuencias políticas, jurídicas y sociales de la reforma energética en México, encierra en el fondo la necesidad de realizar una investigación avanzada en tales materias y de establecer foros permanentes de discusión y análisis, de aprendizaje y difusión, abiertos a todos los sectores sociales concurrentes, como una muestra de la necesaria participación que debemos asumir los académicos, los investigadores, los técnicos, los operadores y todos los interesados en que la opinión de la sociedad mexicana deba estar siempre presente y actuante en la asunción de las grandes decisiones nacionales.

Por ello, el presente artículo, que se fundamenta en el estudio meditado y en nuestra experiencia personal y directa en estas temáticas clave a lo largo de los últimos años en los ámbitos académico, profesional y diplomático dentro y fuera del país, busca contribuir a conformar una nueva escuela mexicana de pensamiento jurídico internacional en el rubro de las fuentes de energía, y un criterio social común que deberán considerar los tomadores de decisiones del país, que tienen en sus manos la revisión, mejora y puesta en marcha de los puntos críticos de la nueva agenda nacional petrolera y energética en el marco de un genuino Estado de derecho y del derecho internacional de la energía presente y futuro.

1 Otros eventos que se han realizado en la UNAM sobre esta importante materia son: la conferencia Energía y Desarrollo, del ciclo Hacia una Política Energética de Estado, organizado por la Facultad de Economía, el Programa Universitario de Energía de la UNAM, y el Senado de la República; la mesa Reforma Energética y Petróleo, en la Facultad de Ciencias; el debate sobre los Ciclos y las Crisis del Mercado Petrolero Mundial y su Impacto en México, en el Centro de Relaciones Internacionales de la Facultad de Ciencias Políticas y Sociales; la conferencia Qué hacer con la Reforma Energética, en la misma Facultad, y el Seminario Yacimientos Transfronterizos de Petróleo, una Perspectiva de Derecho Internacional, en el Instituto de Investigaciones Jurídicas. 


\section{PREMISA CENTRAL}

El tratamiento de estos y otros temas de gran calado requiere de una gran responsabilidad histórica, una memoria fresca y precisa sobre los hechos políticos, económicos, jurídicos y sociales que han moldeado el devenir de los últimos cien años de la historia energética del país y del resto de los Estados de la comunidad internacional; además de un conocimiento profundo y extenso de la materia central a estudiar o a reformar en su caso, en campos aplicables de la tecnología, el derecho interno, el derecho internacional y la adopción de resoluciones gubernamentales y sociales.

Una nueva concepción de la problemática energética exige una visión científica y multidisciplinaria de la realidad geopolítica y geoeconómica nacional y mundial, así como una percepción progresista de las transformaciones del concepto de soberanía y de nueva constitucionalidad, de la metodología empleada para conocer los verdaderos recursos disponibles, de la certeza sobre el ritmo de explotación real impuesto y los alcances de la prospección petrolera, de la adopción de la planeación categórica y no indicativa, y de una política nacional integral energética, que junto con el análisis del contexto mundial actual de las fuentes de energía fósiles y de las fuentes alternas o renovables de energía, nos permitan entender en su justa dimensión - entre otros fenómenos causales-, el funcionamiento de esa entidad difusa e incierta que tendemos a identificar simplemente como mercado mundial del petróleo. ${ }^{2}$

En efecto, el también llamado mercado mundial energético — por su extensión a los demás recursos y fuentes combustibles-, ha sido señalado por todas las doctrinas neoliberales de la modernidad como el sustituto ideal del sistema de derecho internacional al que consideran decadente, anárquico y contrario a sus intereses. Para ellas, el mercado es el nuevo mecanismo ordenador que "todo lo pone en su lugar"; de ahí que hoy muchos individuos, sociedades, empresas y gobiernos esperen de él, por desconocimiento, comodidad o conveniencia, las reglas a cumplir, las fórmulas ideales a seguir $\mathrm{y}$, por ende, las grandes soluciones a los

2 Velázquez Elizarrarás, Juan Carlos, El derecho internacional público en la agenda política de las relaciones internacionales, México, UNAM, Facultad de Ciencias Políticas y Sociales, 2005, pp. 77-114. 
problemas de hoy y de mañana. Nada resulta más falso y riesgoso, para cualquier Estado o sociedad, que partir de este errático supuesto.

Se requiere pues, porque nunca la ha habido en México, una visión de Estado, y no de mercado, en el manejo político y la regulación jurídica de los recursos energéticos de la nación. Y en la sociedad internacional urge, hoy más que nunca, la adopción de un plan mundial de energía que conserve y controle los recursos disponibles, proteja al medio ambiente de la irracional combustión de hidrocarburos propia de esta cuarta revolución industrial, y que distribuya la renta petrolera del orbe con base en el uso eficiente de la energía y los principios del desarrollo sustentable y sostenible.

\section{EL DERECHO INTERNACIONAL DE LA ENERGÍA Y EL MERCADO MUNDIAL DEL PETRÓLEO}

\section{El derecho internacional de la energía}

Grosso modo podemos definir el derecho internacional energético como aquella rama del derecho internacional que tiene por objeto ordenar y regular en su amplio espectro y en la totalidad de sus manifestaciones, la actividad y el comercio internacional de la energía. Y por la complejidad y amplia variedad de su objeto de regulación, el derecho internacional de la energía (DIEn) abarca campos y aspectos del derecho internacional público y del derecho internacional privado, así como del derecho económico, mercantil, administrativo y fiscal ${ }^{3}$ internacionales $\mathrm{y}$, por supuesto, del derecho constitucional internacional o derecho de las organizaciones internacionales; sin olvidar la comprensión que necesariamente tiene el DIEn de aquellos elementos, disposiciones constantes y normas equivalentes del régimen jurídico aplicable a los productos básicos en el comercio internacional. ${ }^{4}$ De ahí que, en los últimos años, una importante corriente doctrinal latinoamericana y otras como la española, la francesa y la italiana, se pronuncien por el manejo del término conceptual de derecho internacional de la energía y de los productos básicos,

3 Uckmar, Víctor (coord.), Curso de derecho tributario internacional, Colombia, Temis, 2003.

4 Witker Velásquez, Jorge, Régimen jurídico de los productos básicos en el comercio internacional, México, UNAM, Instituto de Investigaciones Jurídicas, 1983. 
es decir, lo que los ingleses han dado en llamar Internacional Law of Energy and Raw Materials. ${ }^{5}$

En un sentido lato, la energía como objeto de reglamentación del DIEn ha sido considerada por muchos especialistas como el cuarto factor de la producción. Para demostrarlo se argumenta que: 1) sin energía la tierra no produce, 2) el capital no se transforma ni recompone y 3) el trabajo no se potencia ni rinde más allá de su expresión natural (fuerza de trabajo). Hay muchas formas y manifestaciones de la energía como recurso natural, renovable y no renovable. La energía fósil o de los hidrocarburos (petróleo, carbón, gas, turba, esquistos bituminosos y arenas alquitranadas) es finita y no renovable, al igual que la energía nuclear que se alimenta básicamente de uranio. La energía alternativa, en cambio, es renovable y prácticamente infinita dependiendo de las capacidades técnicas que se apliquen: solar (térmica y fotovoltaíca), geotérmica, hidráulica, eólica, hidrogénica, biomasa o bioconversión, océanomotriz, entre otras.

Pero sobre todas las fuentes conocidas, el petróleo se ha convertido en el recurso energético más importante de la sociedad actual y en el motor de toda la actividad industrial y económica moderna. Además de su importancia económica, el interés por controlar y explotar los principales yacimientos petroleros ha sido el origen de muchos conflictos bélicos entre los Estados. Los hechos convalidan que a medida que se agota este recurso natural no renovable se pone en riesgo tanto la estabilidad económica y política mundial como la viabilidad del paradigma capitalista de progreso, entendido éste en términos de industrialización de mercado. El oro negro aporta el mayor porcentaje del total de la energía que se consume en el mundo y su importancia se ha incrementado de manera acelerada desde sus primeras aplicaciones industriales a mediados del siglo XIX. De manera directa o indirecta, constituye una de las principales fuentes de ingresos de los países: los productores basan su estabilidad económica en la comercialización del recurso, mientras que los países desarrollados obtienen ganancias económicas de su aplicación a la actividad industrial. Por todo ello, el petróleo es el objeto jurídico tutelado más importante del DIEn.

5 Burnell, Meter y Randall, Vicky, Politics in the Developing World, Nueva York, Oxford University Press, 2005 , p. 220. 
Ahora bien, hoy parece no admitir duda el hecho de que por su propia esencia y por la fuente de donde emana, todo el derecho es público. Entonces, si asumimos que el DIEn es derecho internacional y es en sustancia derecho público, estará íntimamente ligado no sólo al mercado mundial energético y a los propios recursos energéticos que se mueven por grandes fuerzas económicas y políticas sino que, lo más interesante - y en ello radica su cuota de mayor complejidad-, es que se hallará conectado invariablemente con los contextos críticos de la política internacional y del sistema político mundial.

En este sentido, en este año clave de 2008 por ejemplo, la construcción del DIEn habrá de considerar que los altos precios del petróleo, el dominio militar estadounidense sobre la región con mayores reservas del combustible y la importancia de nuevos actores económicos como India y China cuya población y crecimiento económico demandan un mayor uso de energía, vuelven a replantear la necesidad de buscar alternativas energéticas viables que, en plena globalización, permitan dar abasto a la creciente demanda de energía fósil tanto para uso industrial como doméstico. Asimismo, la actualización del contenido del DIEn deberá tomar en cuenta que la mayoría de los países del mundo están analizando su panorama energético para identificar estrategias y acciones en los campos tecnológicos, económicos y políticos que les permitan no sólo sostener el nivel actual de uso energético, sino, más relevante aún, ampliar su utilización y mejorar su distribución ante los retos que enfrenta el propio proceso global y el aumento galopante de la población del orbe.

A guisa enunciativa, otros hechos a distinguir por el DIEn son que con excepción de Estados Unidos, Canadá y la Federación Rusa, los principales mercados de consumo se encuentran alejados de los más importantes centros de reservas y producción de petróleo. Europa occidental importa el $97 \%$ de sus necesidades petrolíferas, principalmente de África y Medio Oriente, mientras que Japón tiene que importar el $100 \%$ de lo que consume. Al igual que en otras áreas del comercio internacional, el mercado mundial del petróleo se caracteriza por la aguda desigualdad entre productores-exportadores y compradores de crudo. Las reglas y principios, tanto formales como informales, que rigen la comercialización internacional del petróleo son establecidas por las potencias tecno-industriales y las grandes empresas transnacionales en detrimento de los países productores. Recordemos que el principal intento de éstos por incidir en el comercio internacional del crudo se materializó con la 
creación de la Organización de Países Exportadores de Petróleo (OPEP) que tras un inicio prometedor se vio debilitada por las propias diferencias de criterios y objetivos de los miembros que la componen. Además, varios Estados productores y exportadores de petróleo prefirieron mantenerse al margen de dicha organización — por ejemplo: México, Rusia, Reino Unido y EUA - a fin de poder comercializar su recurso energético de forma bilateral y aprovechando unilateralmente las coyunturas internacionales. ${ }^{6}$

Como ya señalamos, el tema de la actividad y la comercialización internacional del petróleo reviste características particulares que merecen ser estudiadas por la ciencia jurídica internacional desde al menos dos de sus principales ramas, a saber: el derecho internacional público (DIPb) y el derecho internacional privado (DIPr). Al primero le compete la configuración del DIEn y el desarrollo de sus fuentes, el ejercicio soberano de los Estados para explotar y comercializar sus recursos naturales, la regulación de las acciones políticas y, en su caso, la prevención o corrección de las consecuencias del poder y del conflicto derivadas de la actividad energética; en tanto que al segundo, le corresponde regular la forma y las vías en que se desenvuelve el comercio internacional del petróleo, la aplicación conflictual de los órdenes jurídicos internos de los Estados, la realización de contratos internacionales y el establecimiento de los medios, métodos y mecanismos necesarios para la solución de diferencias surgidas de la comercialización, tanto del principal energético del planeta como de los demás recursos que comportan el abanico de fuentes utilizadas.

El derecho soberano de los Estados para explotar sus recursos naturales constituye el pilar fundamental del DIEn. Esta rama del derecho de gentes contempla los principios y normas jurídicas que los Estados implementan en actividades relacionadas con la explotación y comercialización de los recursos energéticos, así como en la solución de controversias surgidas de tales actividades, sin dejar de mencionar, el desarrollo de nuevas fuentes de energía y el uso pacífico de las mismas. ${ }^{7}$

6 Para mayor detalle consúltese mi tesis de licenciatura, La crisis energética internacional (1970-1981). Radicalismo y debilitamiento de la OPEP, México, UNAM, Facultad de Ciencias Políticas y Sociales, 1982, 268 pp.

7 En este sentido, el DIEn también se encuentra estrechamente vinculado con el $\mathrm{DIPb}$ y con el DIPr por sus sujetos (Estados, organismos internacionales y empresas 


\section{Reflexiones generales sobre las fuentes del derecho internacional de la energía}

No dudamos en afirmar que las fuentes del DIEn son esencialmente fuentes de derecho internacional público. De acuerdo con Fernando Heftye Etienne, ${ }^{8}$ las fuentes del DIEn no difieren mucho de las del DIPb, empero, presentan algunas particularidades. En las relaciones internacionales modernas existen una serie de sectores de la actividad económica y política que han cobrado existencia propia y exigen un marco normativo particular, es el caso preponderante del sector energético y del mercado mundial del petróleo, no sólo por su trascendencia geoeconómica y geopolítica sino por el impacto que tienen en el diseño e implementación de políticas nacionales. Así, llama la atención que en el último medio siglo la postura que han asumido los Estados en estas materias ha sido fundamental para el desarrollo de varios institutos que forman parte del $\mathrm{DIPb}$, por ejemplo, la nacionalización-expropiación, la soberanía estatal sobre los recursos naturales, los embargos comerciales, los bloqueos económicos, las sanciones, la naturaleza jurídica de las resoluciones de organismos internacionales, la protección y control de las reservas y yacimientos, los regímenes de administración condominal, las tesis del patrimonio natural mundial, los nuevos métodos de adquisición de soberanía territorial, entre otros más de enorme importancia.

En todas y cada una de estas instituciones, es frecuente hallar una participación sustancial del sector energético en la creación de normas ad hoc para abordar los múltiples y complejos problemas que el mismo encierra por su propia naturaleza primaria y de generación de conflictos de todo género. $\mathrm{Y}$ es que en el ámbito de la energía participan cotidianamente agentes económicos y políticos tan diversos como los propios Estados, los organismos interestatales, las sociedades mercantiles transnacionales y las empresas multinacionales, con objetivos generalmente contradictorios que resaltan la necesidad de establecer un marco normati-

transnacionales), fuentes (tratados y contratos internacionales, costumbre internacional, principios generales de derecho, jurisprudencia internacional, doctrina, y leyes nacionales en la materia), y sus métodos (contratación y arbitraje internacionales), y con el derecho internacional económico por las reglas aplicables a la comercialización internacional del petróleo en específico.

8 Heftye, Fernando, "Las fuentes del derecho internacional energético", Regulación del sector energético, México, Secretaría de Energía-UNAM, 1997, p. 523. 
vo particular y especial. Pero, en el presente artículo, no buscamos justificar la existencia de un DIEn como una rama autónoma del DIPb, o como un capítulo de la parte especial del DIPr, sino simplemente analizar de manera general las diversas fuentes que serían aplicables al marco jurídico internacional que rige en este rubro específico. ${ }^{9}$

\section{A. Revisión de la doctrina clásica de las fuentes del derecho internacional y del derecho internacional de la energía}

Por fuentes se entiende las formas de manifestación del derecho internacional. Son los procedimientos o canales a través de los cuales se crean, modifican o extinguen normas jurídicas de naturaleza internacional. A efecto de ubicar las fuentes del DIEn conviene entonces analizar en sus rasgos esenciales las fuentes del DIPb, toda vez que por más discutible que sea la autonomía del primero, necesariamente tendría que encuadrarse dentro del segundo, con una importante excepción - que a su vez reafirma la particularidad del DIEn - que es la participación de las empresas transnacionales y multinacionales, amén de las organizaciones mixtas (público-privadas) e incluso las no gubernamentales, entes que no son considerados como sujetos de DIPb.

Tradicionalmente se ha tomado el artículo 38 del Estatuto de la Corte Internacional de Justicia, que tiene su antecedente en el artículo del mismo número del Estatuto de la Corte Permanente de Justicia internacional, como indicador oficial de las fuentes del derecho internacional general. La doctrina es unánime en este sentido, sin embargo, existe una gran discrepancia en lo que se refiere a la interpretación de sus alcances.

El artículo 38 del Estatuto dice textualmente:

1. La Corte, cuya función es decidir conforme al derecho internacional las controversias que le sean sometidas, deberá aplicar:

a) Las convenciones internacionales, sean generales o particulares, que establecen reglas expresamente reconocidas por los estados litigantes;

9 Como lo enfatiza Fernando Heftye, op. cit., nota 8, p. 522, profundizar sobre la creación de una rama autónoma del derecho requiere mucho más tiempo, dedicación y espacio que el que aquí disponemos. De ahí que por ahora sólo se busque hacer un análisis general de la aplicación particular de las fuentes del derecho internacional en un sector económico y político específico. 
b) La costumbre internacional como prueba de una práctica generalmente adoptada como derecho;

c) Los principios generales de derecho reconocidos por las naciones civilizadas:

d) Las decisiones judiciales y las doctrinas de los publicistas de mayor competencia de las distintas naciones, como medio auxiliar para la determinación de las reglas de derecho, sin perjuicio de lo dispuesto en el artículo $59 .{ }^{10}$

2. La presente disposición no restringe la facultad de la Corte para decidir un litigio ex aequo et bono, si las partes así lo convienen.

En cuanto a sus alcances, la interpretación del artículo 38 del Estatuto de la CIJ no es muy uniforme en la doctrina de derecho internacional, como lo hace notar el ius internacionalista Alfred Verdross, ${ }^{11}$ sobre todo en lo que se refiere a dos aspectos: el carácter ejemplificativo o enumerativo en las fuentes señaladas en dicha disposición y en la importancia jerárquica en que pudieran estar enumeradas las fuentes. Al respecto, hay una corriente mayoritaria en la ciencia del derecho internacional que considera que el artículo 38 in comento tiene una terminología puramente descriptiva y "no tiene por objeto restringir en forma alguna la operación de las fuentes que se describen". ${ }^{12}$

La interpretación contraria, es decir, la que considera que no hay más fuentes del derecho internacional que las señaladas en el precitado artículo 38, representa un obstáculo importante al desarrollo del derecho internacional, en su nivel general y en el del DIEn. Y es que la adecuación del derecho internacional a las relaciones internacionales en constante transformación no sería posible con la existencia de un sistema cerrado de fuentes del derecho. Igualmente, hay que ponderar la reivindicación que hacen los países de Asia y África en el sentido de que no participaron en la elaboración del sistema jurídico internacional, y un sistema li-

10 El artículo 59 del Estatuto de la Corte Internacional de Justicia establece que "d) Las decisiones de la Corte no son obligatorias sino para las partes en litigio y respecto del caso que ha sido decidido".

11 Verdross, Alfred, "Les principes generaux de droit dans systeme des sources du droit international public", Hommage a Paul Guggenheim, Suiza, 1968, p. 521.

12 Virally, Michel, "Las fuentes del derecho internacional", en Sorensen, Max (ed.), Manual de derecho internacional público, México, UNAM, Facultad de Ciencias Políticas y Sociales, 1998, p. 153. 
mitado de fuentes obstaculiza la creación de normas jurídicas de carácter más justo y democrático. ${ }^{13}$

En lo que concierne a la importancia jerárquica en que pudieran estar enumeradas las fuentes, aunque algunos autores opinan que los tratados constituyen la fuente más importante de normas de derecho internacional, ${ }^{14}$ en la práctica internacional esto no es así, ya que el juzgador ha aplicado indistintamente las fuentes sin tomar en cuenta un orden jerárquico. ${ }^{15}$ Por ejemplo, tenemos que en Caso Nicaragua contra Estados Unidos (por el minado de puertos, 1993), la Corte tuvo que resolver la controversia con base exclusivamente en la costumbre internacional. En nuestro punto de vista, por un lado, el artículo 38 del Estatuto de la CIJ no debe verse como un contenedor que aprisione la manifestación de la normatividad jurídica internacional, además de que se deben tomar en cuenta las transformaciones cualitativas de la sociedad global; y por el otro, descuella una corriente doctrinal muy crítica de dicho artículo que incluye a las mismas fuentes como objeto de su disertación, pero el problema es que no se ha generado una doctrina que se separe totalmente de este precepto legal, pues a lo más a que se ha llegado es a ponerlo en la mesa de las discusiones y a interpretarlo en forma amplia, es decir a no considerarlo cerrado. En definitiva, como lo enfatizan Becerra Ramírez y Wolfgang Friedmann, el mundo de la actual sociedad global es muy diferente al que existía en 1919, cuando entró en vigor el antecedente del actual artículo 38 .

El derecho internacional ha seguido evolucionando y debe desarrollarse de acuerdo con las necesidades de la comunidad contemporánea, cuya característica sobresaliente es la globalización de los actores, los procesos y las interacciones; esto es, Europa ya no es el centro creador

13 Becerra Ramírez, Manuel, Derecho internacional público, México, UNAM, Instituto de Investigaciones Jurídicas-McGraw-Hill, 1997, p. 40. Este criterio lo hemos tomado textual del autor porque refleja de manera muy clara lo que queremos expresar. Pero además agrega un hecho determinante: que el derecho internacional seguirá evolucionando de acuerdo con las necesidades del mundo contemporáneo, cuya característica sobresaliente es la internacionalización total de las relaciones internacionales.

14 Jiménez de Aréchaga, Eduardo, Curso de derecho internacional público, Montevideo, 1979, t. I, p. 55.

15 El mismo criterio expresó Adolfo Miaja de la Muela: "no implica grados diferentes de jerarquía al menos entre tratado y costumbre... los principios generales del derecho pueden ser utilizados como reglas supletorias de la carencia de tratado y costumbre", Introducción al derecho internacional público, 7a. ed., Madrid, 1979, p. 98. 
del derecho, ni son 51 los Estados que conforman la organización universal. Las relaciones internacionales son más complejas —en especial las relativas al mundo de los energéticos- - y se requiere una mentalidad más científica y abierta para aceptar y entender las nuevas manifestaciones jurídicas internacionales, como son las referidas a las materias y el objeto del DIEn.

Por su parte, la jerarquía general entre las fuentes de derecho no constituye un problema si se trata de dilucidar entre diversas normas concretas, sino más bien si se cae en la cuenta de que cada fuente de derecho tiene sus propias ventajas e inconvenientes. Hasta ahora parece quedar claro el hecho de que las fuentes tradicionales, los tratados y la costumbre, ya no son suficientes para una jurisprudencia efectiva en materia petrolera o energética; se requiere de otras fuentes, de otros medios, deben utilizarse otras bases de interpretación. El mundo global de la energía — que todo lo mueve - así lo demanda y establece.

\section{B. Los tratados internacionales}

Los tratados representan el noyau dur (núcleo duro) del derecho internacional general y del energético. Comparados con la costumbre y los principios generales de derecho, las ventajas son manifiestas: claridad, precisión, carácter explícito, evidencia y vinculación indudable de las partes. Al ser necesario el voto del parlamento o del congreso de cada Estado signatario para su ratificación en la mayoría de los casos, los tratados disponen de una alta legitimidad. Aunque no son siempre universalmente ratificados, pueden contribuir a la clarificación del derecho existente y constituir el punto de partida para arribar a un desarrollo de la costumbre. Sin embargo, las partes que no son signatarias o contratantes no pueden de ningún modo ser vinculadas por los tratados $\mathrm{y}$, con frecuencia, no experimentan más que un mínimo consenso en un campo estrechamente acotado o bien se limitan a los grandes principios cuya aplicación directa no es del todo fácil o posible. Sólo una vasta codificación que permita el ensamble de un campo jurídico determinado puede compensar esta carencia. ${ }^{16}$

16 A pesar de las desventajas señaladas, que exageran varios tratadistas europeos franceses y anglosajones, los tratados representan — para quienes hemos dedicado parte de nuestra vida académica a su estudio y difusión-, la expresión jurídica más acabada 
Los tratados internacionales son fuente del DIEn en la medida que regulan las relaciones entre los Estados en la materia o designan la voluntad de los mismos para crear organismos internacionales especializados en cuestiones energéticas. A través de tratados internacionales en materia de recursos de energía fueron establecidas las principales organizaciones interestatales en el rubro como la OPEP en 1960, la OPAEP en 1968, la Organización Latinoamericana de Energía (OLADE) en 1970, la Alianza Regional Petrolera Latinoamericana (ARPEL) en 1967 y el Organismo Internacional de Energía Atómica (OIEA) en 1957. Además, es por medio de estos instrumentos que se regula la comercialización oficial y la compraventa de hidrocarburos entre Estados soberanos, como por ejemplo, los acuerdos México-Estados Unidos, México-Canadá o Canadá-Estados Unidos, para el suministro de gas natural, gas licuado, carbón, petróleo o, incluso, uranio y otros materiales estratégicos y radiactivos usados como combustibles.

Por otra parte, hoy se dispone de un amplio abanico de tratados no constitutivos de organismos internacionales que son aplicables, directa e indirectamente, al sector de la energía, como es el caso de los relativos a la protección y preservación del medio ambiente (son más de doscientos a nivel multilateral registrados por el programa de las Naciones Unidas para el Medio Ambiente de la ONU), que podrían ser objeto de análisis más profundos posteriormente. Por el momento, baste destacar el hecho de que en el DIEn los acuerdos entre Estados, a través de la vía conven-

de las relaciones internacionales contemporáneas y la fuente suprema y esencialísima del derecho de gentes. Los tratados son el pilar fundamental del sistema jurídico supranacional, fomentan las relaciones entre las partes, y hacen posible la creciente internacionalización de la comunidad dentro de normas que contribuyen a la sistematización y desarrollo del derecho internacional general y en este caso, del DIEn. En cualquier rama del derecho internacional los tratados son fuente de derechos y obligaciones internacionales particulares, además de excelentes coadyuvantes en la formación de normas generales. Más numerosos que en cualquier tiempo pasado, con ellos se edifican la coexistencia y la cooperación en un amplio espectro de materias, como la petrolera-energética o la nuclear, donde se identifican intereses comunes y se evidencia la interdependencia de los miembros de la actual sociedad global. Ésta requiere, por ello, cada vez más de normas y organización específicas, las cuales no pueden ser formuladas por la costumbre, lenta e imprecisa. Por ejemplo, consideremos que no puede conseguirse la cooperación internacional en ciertos campos de alta seguridad como las fuentes tradicionales y las nuevas de energía, o el gran abanico de productos básicos y materias primas estratégicas, a menos que sean reguladas por tratados internacionales. 
cional, se han enfocado a la colaboración internacional para afrontar una problemática determinada, generalmente mediante el establecimiento de agencias interestatales encargadas de gestionar los intereses energéticos comunes de sus naciones asociadas.

A diferencia de otras ramas del DIPb - como el derecho ambiental, el social o el del desarrollo, en las que cobra mayor importancia la revisión cuidadosa de los tratados suscritos entre diversos Estados-, en el DIEn los acuerdos de voluntades son celebrados entre Estados y personas jurídicas o morales — como las denomina el DIPr—, razón por la que no pueden ser reconocidos como tratados, sino como contratos privados, pues tanto las sociedades mercantiles multinacionales como las empresas trasnacionales activas no tienen subjetividad pública internacional, es decir, no son consideradas sujetos de DIPb. De esta suerte, los grandes monopolios petroleros como las llamadas "Siete Hermanas" que juegan un papel histórico dominante en el mercado mundial del petróleo, no pueden ser controladas o reguladas a través de tratados o pactos concertados únicamente entre Estados - ellas mismas cimentaron su poder a partir del momento en que suscribieron los Acuerdos de Achnacarry (de orden exclusivamente privado), en 1929-.

Aun así, los contratos son fuente del DIEn ya que las Partes se obligan a cumplir con determinados compromisos mediante el ejercicio de la autonomía de la voluntad. El contrato se convierte en fuente de derecho una vez que las normas establecidas en el mismo son reconocidas y aplicadas por una instancia judicial competente. En añadidura, hay que tener presente que los Estados en sus actuales agendas de negociación para configurar bloques de integración regional —y ahí están los ejemplos de la Unión Europea, la ANSEA y recientemente la Unión Africana-, vía tratados multilaterales, incluyan la denominada variable energética contractual, esto es, asuman obligaciones precisas y de mediano y largo alcance en torno al sector energético, pues, al igual que ocurre con la variable ambiental o la de derechos humanos, lo consideran vital para poner en marcha toda iniciativa de cooperación. Por ello, no cabe duda acerca de la preponderancia que hoy tienen los tratados internacionales como fuente primaria del DIEn.

Como se puede apreciar, el derecho internacional de los tratados en materia energética, se desprende y se autonomiza del derecho internacional general y va más allá del nivel que ocupan las fuentes tradicionales del orden jurídico que rige para toda la comunidad de Estados. Constitu- 
ye, de hecho, una de las disciplinas que más se ha desarrollado en los años recientes, siguiendo el ritmo dinámico y vertiginoso del mercado mundial de la energía y de la política internacional en la materia. De ser un derecho que se fue formando en la práctica internacional, con las Convenciones de Viena de 1969, 1975, 1986 y otras a la fecha, amén de los acuerdos y resoluciones de los organismos internacionales energéticos que operan actualmente, y los reglamentos especializados en rubros del comercio internacional de los combustibles y las materias primas, está pasando a ser un derecho codificado que converge con el derecho internacional consuetudinario, con un carácter innovador y abierto a la introducción de nuevos principios y criterios de interpretación en estas importantes disciplinas.

\section{La costumbre internacional o derecho internacional consuetudinario}

Una parte importante de la doctrina moderna considera que la costumbre universal es superior al derecho convencional en su campo de aplicación porque es aplicable a todos los Estados. Sin embargo, no tiene la claridad ni la seguridad jurídica del derecho convencional. En la práctica se observa cómo la noción de principios generales de derecho remite a su uso en la costumbre y no tanto a los principios generales del derecho en un sentido técnico. La costumbre y los referidos principios tienen en común el hecho de que no requieren ser formalizados, en la medida en que se derivan del comportamiento estatal y de las declaraciones de opinión del derecho nacional.

La teoría del derecho consuetudinario ha tenido una notable evolución en los últimos lustros y se encuentra en un proceso de transformación continua. El derecho de la costumbre clásico constituía el resultado de una observación de comportamiento efectivo del mayor número posible de Estados, deviniendo en derecho consuetudinario en el momento en que se materializaba la convicción de los Estados sobre el carácter obligatorio de su comportamiento. Sin embargo, dentro de la sociedad internacional actual, es apenas posible observar, a nivel universal, el comportamiento efectivo de un número suficiente de Estados, a menos que, de otro modo, los contactos diplomáticos en la ONU, la OPEP, la AIE, la ARPEL o la OLADE y en otras organizaciones internacionales, se intensifiquen de manera que los argumentos jurídicos de los Estados sean re- 
lativamente fáciles de discernir, como ocurre con los tratados formales que resultan de esta suerte de poder legislativo internacional.

En este sentido, el derecho de la costumbre está derivando poco a poco de declaraciones estatales más o menos oficiales, además de la doctrina fuertemente influenciada por la opinión pública. Se trata, dentro de la célebre terminología de René Dupuy, de una "costumbre salvaje" diferente de una "costumbre moderada" derivada del comportamiento efectivo de los Estados. ${ }^{17}$ Él también observa, en el campo de los energéticos, un desapego del derecho internacional con relación al comportamiento efectivo de los Estados. Según Bruno Simma y Philip Alston: "El proceso de elaboración de la ley se ha tornado así en un ejercicio auto-contenido de retórica". ${ }^{18}$ Los dos autores hablan también de una "crisis de identidad" del derecho consuetudinario.

En el derecho internacional general y en el DIEn, la relación entre los tratados multilaterales y el derecho consuetudinario es particularmente delicada. Por un lado, los tratados multilaterales resultan frecuentemente de codificar el derecho de la costumbre existente. Por el otro, si bien el derecho consuetudinario anterior continúa vigente para las partes no contratantes, éste, en razón de un tratado que está en vigor, no se mantiene tal cual. Desde una óptica tradicional, la Corte Internacional de Justicia explica: "Para que una regla convencional sea considerada como una norma de derecho internacional general, se requiere al menos que, junto con un largo período de observancia, muestre una participación muy amplia y representativa en la convención, y satisfaga la condición de comprender a todos los Estados interesados". ${ }^{19}$ En su jurisprudencia posterior, la CIJ fue menos severa y flexibilizó sus criterios para el establecimiento de una norma general de derecho internacional a partir de una disposición convencional. ${ }^{20}$ En suma, debe siempre tenerse presente la relación entre costumbre y tratados internacionales, y no visualizarlos como fuentes totalmente independientes entre sí.

17 Dupuy, R. J., La communauté internationale, Mélanges offerts á Charles Rousseau, París, Editions A. Pédone, 1974, pp. 75 y 76.

18 Simma, Bruno y Alston, P., "La identidad del derecho consuetudianario", Italian Year Book of International Law, vol. 12, 1992, p. 89.

19 Véase el caso de la Plataforma Continental del Mar del Norte, Corte Internacional de Justicia, Rec. 1969, pp. 3 y 73.

20 Véase Mendelson, Cincuenta años de la CIJ, Países Bajos, 1996, p. 72. 
Al igual que en el DIPb, el DIEn también contempla en sus raíces normas de costumbre internacional; está constituido por principios y normas de origen consuetudinario que se fueron creando y perfeccionando a medida que se incrementó la comercialización de recursos energéticos, principalmente, el petróleo. En efecto, el descubrimiento de grandes yacimientos a principios del siglo XX en varios países subdesarrollados acarreó como consecuencia ineludible, la presencia de compañías transnacionales dispuestas a explotar a fondo dichos recursos; y el país huésped, si bien ejercía la soberanía sobre ellos, se limitaba a otorgar concesiones sobre los mismos recibiendo a cambio contraprestaciones simbólicas (hasta la creación de la OPEP, el Estado receptor de hecho sólo participaba al mínimo en la renta petrolera). Como lo enfatizan Heftye y A. Massarat, en ese momento histórico la costumbre prevaleciente dictaba un papel pasivo por parte de las naciones huéspedes, como fue el caso de México. Empero, con el paso del tiempo se dan los movimientos de descolonización y de un nuevo orden económico internacional, auspiciados por la ONU, donde se involucraba particularmente al sector energético a nivel planetario.

Surge así la resolución adoptada por la Asamblea General en torno a la soberanía permanente de los Estados sobre los recursos naturales, que se fortalece con la aprobación de la Carta de Deberes y Derechos Económicos de los Estados en 1975, para dar inicio a una etapa más en la negociación de los nuevos términos de intercambio económico y comercial de los recursos energéticos, principalmente los hidrocarburos. Ese importante período demuestra, entre otros aspectos, el papel destacado que puede jugar el derecho consuetudinario en la formación del DIEn; pero advirtiendo que - por la novedad relativa del sector energético en las relaciones internacionales-, este tipo de costumbre es de la llamada "instantánea", es decir, la que no exige la repetición de una conducta en el tiempo, sino que se da a través de la simultaneidad y multiplicidad, dando por satisfecho este elemento básico en la costumbre tradicional. Esta práctica se observa en ramas particularmente dinámicas como el derecho espacial o el derecho del mar, cuya máxima expresión, la III Convemar o Carta del Mar de 1982, contiene diversas disposiciones perfectamente aplicables al DIEn.

En un balance estricto, podemos afirmar que las normas consuetudinarias del DIEn se han ido modificando y perfeccionando a lo largo del tiempo; debido, principalmente, al acelerado crecimiento del mercado 
petrolero internacional, así como de una cada vez mayor participación de los países productores y exportadores (en su mayoría países en vías de desarrollo) en la fijación de precios del crudo y en la estructuración de comercio internacional de dicho recurso. Al igual que en el DIPb, la costumbre energética se ha ido incorporando en los tratados y contratos de la materia, pero su desventaja persiste, esto es, su falta de precisión y la dificultad de determinar cuándo una costumbre está en plena vigencia o cuándo esa vigencia plena es todavía discutible, ya sea porque la norma consuetudinaria ha caído o está cayendo en desuso, o porque estando en formación no se ha consolidado debidamente. Para el DIEn, esta situación es especialmente relevante, por lo que debe evitarse la imprecisión a través de la conclusión de tratados o convenciones multilaterales, es decir, intensificar la codificación del orden normativo internacional energético, transformando a la costumbre energética en derecho energético escrito. De ahí que, igual que en el derecho interno la ley no ha eliminado totalmente a la costumbre, tampoco es de prever que en el derecho internacional general o en el DIEn los tratados eliminen a la costumbre, que seguirá teniendo la función esencial de facilitar la adaptación del derecho a las realidades cambiantes de la sociedad global energética. ${ }^{21}$

Finalmente, cabe advertir que en el DIEn el problema de determinar la naturaleza jurídica de la costumbre es, en el fondo, el problema central del derecho internacional, o sea, es relativamente fácil admitir la fuerza obligatoria de los tratados, pero es muy difícil determinar el origen de la fuerza obligatoria de la costumbre y discernir su naturaleza jurídica. De ahí que seamos simpatizantes de las teorías sociológicas modernas, para las cuales la costumbre surge de la vida en sociedad, es un hecho social, y se impone a los Estados, no teniendo éstos otra opción que comprobar su existencia. La costumbre es, en suma, una fuente dinámica con una gran capacidad de adaptación a las realidades nacionales e internacionales cotidianas, lo cual es sumamente apreciado cuando el objeto de regulación del derecho lo constituyen entidades y fenómenos tan cambiantes y dinámicos como el mercado mundial de la energía y sus agentes transnacionales.

21 Emanuelli, Claude, Droit internacional public. Contribution á l'étude du droit internacional selon une perspectiva canadienne, Montreal, Wilson \& Lafleur, 2004, pp. 141-160. 


\section{Los principios generales de derecho}

El antes citado artículo 38, 1 c) del Estatuto de la CIJ establece que la Corte deberá aplicar "los principios generales del Derecho, reconocidos por las naciones civilizadas". Esta disposición ofrece dificultades bastante grandes para determinar su contenido exacto. Los principios generales de derecho, en efecto, son distintos de la costumbre, pero en ocasiones es complicado deslindar ambos conceptos; tampoco puede considerarse que sean principios de derecho natural, porque se establece claramente que sean "reconocidos por las naciones civilizadas". Desde nuestro punto de vista, un modo de aproximación al entendimiento de lo que son los principios generales del derecho, sería el intentar distinguirlos de los principios del derecho internacional general y, consecuentemente, del DIEn. Aunque el Estatuto de la Corte Internacional de Justicia pasa por alto tal clasificación, creemos, sin embargo, que hay lugar para hacer una diferencia entre estos diferentes sistemas de principios. ${ }^{22}$

La CIJ, en su sentencia relativa al Caso del oro monetario (o "amonedado" como también se le conoce) del 15 de junio de 1954, emplea el término de principios del derecho internacional, al referir “...un principio del derecho internacional bien establecido e incorporado en el estatuto, a saber, que la Corte no puede ejercer su jurisdicción respecto a un Estado, si no es con el consentimiento de este último". En este punto, resalta la distinción que hace Verdross de ambos principios, porque ilustra de

22 Principios generales del derecho. En este punto el Estatuto se refiere seguramente a aquellos principios que son aceptados en el derecho interno de cada Estado, y que son susceptibles de aplicación internacional. Esta última precisión elimina ciertos principios generales del derecho interno que no pueden trasladarse al campo de las relaciones interestatales e internacionales, como sería el principio de que las personas pueden recurrir unilateralmente al juez, que actualmente resultaría inaplicable a los Estados, a causa de la diferente estructura de la sociedad global. Principios del derecho internacional. Serían aquellos que no tienen su origen en el derecho interno, sino que son propios del derecho internacional. En la vida de las naciones se manifiestan porque son invocados por los Estados o el juez internacional, sin mencionar expresamente su fuente, y al actuar de esta manera no están creando la norma, sino que, por el contrario, la consideran tan evidente que, por parecerles axiomática, no tratan de justificarla o fundamentarla. Esta categoría de principios es mucho más difícil de distinguir de la costumbre internacional que de los principios generales de derecho. En realidad, quizá el único criterio de distinción sería la permanencia, pues mientras la costumbre evoluciona, los principios del derecho internacional, por su mismo carácter de principios, de grandes líneas rectoras, deben permanecer inmutables. 
modo claro el problema: "Los principios del derecho de gentes, son reglas aceptadas directamente en la práctica internacional como siendo de derecho, mientras que los principios generales del derecho han sido primero reconocidos por los Estados en su derecho interno".

Retomando lo estipulado por el artículo 38 del Estatuto de la CIJ, su contenido ha sido interpretado por la mayoría de los doctrinarios en el sentido de que al hablar de los principios generales del derecho se refiere exclusivamente a los principios del derecho nacional, principios que, en virtud de su aplicabilidad universal, serían traspasables al derecho internacional. Al posar este precepto en el reconocimiento de tales postulados por las naciones civilizadas, se sobreentiende que su sentido es lato, esto es, que comprende a la totalidad de los Estados. Empero, el debate sustancial, a nuestro modo de ver, no gira sólo en torno a los autores sustantivos de la existencia misma de los principios de derecho internacional independientes, sino de saber si éstos caen en el supuesto comprendido por el artículo 38, o bien si ellos derivan de normas convencionales o de costumbres concretas. Para la práctica, la polémica no es de una importancia menor.

Los principios generales del derecho son comunes a todos los sistemas jurídicos que se conocen en el mundo. Observan algunas particularidades en su aplicación dependiendo de la tradición jurídica de que se trate (civil law, common law, derecho socialista, etcétera). Algunos estudiosos del jus gentum han puesto en duda que estos principios constituyan una verdadera fuente del derecho internacional, ya que de ellos no se deriva ninguna norma. Sin embargo, toda vez que se entiende por fuentes las formas de creación o manifestación del derecho internacional, en consecuencia, tales principios sí constituyen auténticas fuentes del derecho internacional general y del DIEn.

Pero no hay que confundir, como frecuentemente se hace, los principios generales de derecho con los de derecho internacional que tienen un origen consuetudinario, o bien se encuentran plasmados en tratados internacionales, como la Carta de San Francisco, la Carta de Addis Abeba, la Conferencia Internacional que creó la Agencia Internacional de Energía o la Carta de Bagdad que estableció la OPEP, tan sólo para referirnos grandes entidades interestatales energéticas. También cabe señalar que actualmente parte de la discusión doctrinal se centra, más que en la existencia de principios generales de derecho internacional - lo cual ya no admite duda-, en la en la cuestión de saber si tales principios que señala 
el artículo 38 párrafo 1 del Estatuto de la CIJ pueden derivar de principios internacionales. El asunto lo podemos resumir afirmando que, en derecho internacional de la energía son aquellos principios del orden jurídico interno que pueden ser extrapolados al ámbito internacional energético. $^{23}$

En el ámbito particular del DIEn, como en el de cualquier rama del derecho, en el sistema jurídico que sea, es comprobable la plena vigencia de los principios. Los juzgadores de los diferentes Estados, los agentes económicos y políticos que participan en las diversas transacciones, los juristas de distinta ideología y formación, todos ellos, reconocen, respe$\tan$ y, en su caso, aplican estas máximas rectoras. En cuanto a su naturaleza y alcance, se acepta su carácter subsidiario y su aplicación supletoria, si no existe un tratado o contrato o norma consuetudinaria aplicable al caso concreto. Incluso en las últimas décadas, en varias sentencias de tribunales arbitrales internacionales que han conocido de controversias en materia energética, se hace referencia expresa a algunos de estos principios. En el ámbito del DIEn, los principios generales del derecho se encuentran incorporados en los tratados, contratos y la costumbre internacional y son aplicados por las instancias judiciales y arbitrales encargadas de interpretar las normas consagradas en tales instrumentos.

\section{E. La jurisprudencia internacional}

Señala el artículo 38 del Estatuto de la CIJ en los relativo a las decisiones judiciales y la doctrina: “d) Las decisiones judiciales y las doctrinas de los publicistas de mayor competencia de las naciones como medio auxiliar para la determinación de las reglas de derecho sin perjuicio de lo dispuesto en el artículo 59". Este último prescribe: "las decisiones de la Corte no son obligatorias sino para las partes en litigio y respecto del caso que ha sido decidido"; de lo que podemos deducir que las decisiones judiciales y la doctrina son solamente medios auxiliares, o sea, no son una verdadera fuente, ya que una sentencia no puede basarse exclusivamente en decisiones judiciales anteriores.

23 Lo mismo ocurre en el derecho internacional del medio ambiente (DIMA). Véase, Velásquez Elizarrarás, Juan Carlos, El estudio de caso en las relaciones jurídicas internacionales. Modalidades de aplicación del derecho internacional, México, UNAM, Facultad de Ciencias Políticas y Sociales, 2007, Caso 20 Aplicación dinámica de los principios generales del DIMA, pp. 451-464. 
Además, las decisiones del máximo tribunal tienen las características de relatividad: son válidas para las partes y el caso concreto que resuelven de acuerdo con lo señalado por el propio numeral 59. Y sobre la doctrina, no se refiere a cualquier doctrina, sino sólo la de los publicistas de mayor competencia de las distintas naciones, también como un medio auxiliar del juzgador, y esto es entendible dado que el especialista opina e investiga pero no crea derecho internacional. Profundicemos un poco al respecto. ${ }^{24}$

Las sentencias judiciales no obligan al juez internacional, y su utilidad estriba en que son indicadores del derecho internacional, fundamentalmente de la costumbre y de los principios generales de derecho. Las decisiones de los tribunales internos también tienen importancia como medio de conocer la actitud de los Estados en determinadas cuestiones relativas al derecho internacional y al DIEn, pero, es obvio, no pueden ser consideradas como fuentes verdaderas porque no tienen el papel de órgano del Estado encargado de las relaciones internacionales. Además, los juicios de los tribunales nacionales no son mencionados de manera expresa en el precitado artículo $38 \mathrm{y}$, aunque no asumen una posición competente y jurídicamente obligatoria, forman parte de la práctica estatal y pueden contribuir a la formación del derecho consuetudinario. Al mismo tiempo, resultan indispensables para la mejor comprensión de los principios generales de derecho, particularmente en ramas muy especializadas y actuales como la internacional petrolera, y la energética abierta a todos sus campos como el de la energía nuclear.

En el desarrollo del DIEn se observa particularmente que - con mayor énfasis a raíz del actual boom petrolero-, a pesar de las reservas que puedan plantearse a la jurisprudencia como fuente auténtica, en los tribu-

24 A pesar de las limitaciones que se aducen respecto de esta fuente auxiliar, la CIJ ha dado, en la práctica, una relevancia mayor que la que en principio parece corresponderle. Al respecto, algunos ius internacionalistas como el danés Max Sorensen, consideran que la Corte se remite constantemente a sus decisiones anteriores; que el valor ilustrativo de estas decisiones depende de la autoridad de la Corte y del procedimiento mediante el que se dictan y no de su fuerza obligatoria; razón por la que la confianza en las decisiones judiciales y arbitrales (éstas más comunes en la solución de controversias sobre petróleo y energía) para la determinación de las normas de derecho, hoy es una parte relevante y habitual de la práctica internacional, lo cual permite en añadidura "conferir una certidumbre a las normas consuetudinarias, que de otro modo no tendrían, y así facilitan en gran parte su aplicación". Véase Sorensen, Marx, op. cit., nota 12, p. 178. 
nales internacionales, convencionales y arbitrales, existe una tendencia creciente a apoyarse en anteriores decisiones como expresión del derecho existente. En el DIEn cabe advertir la particular relevancia que tienden a desempeñar las decisiones arbitrales y el derecho consuetudinario de naturaleza comercial, petrolera y energética. La jurisprudencia en estas materias contribuye muy directamente al funcionamiento de la costumbre y complementa el todavía incipiente derecho convencional energético, amén de desempeñar con frecuencia un papel decisivo en el desarrollo de un DIEn más moderno y completo, sin llegar a constituir, sin embargo - como ocurre en el derecho internacional general —, una fuente distinta por sí misma.

Para nosotros es claro que en el DIEn, al igual que en el DIPb, la jurisprudencia tiene un valor que no debe despreciarse, más aun si se aplican criterios e institutos propios de la familia jurídica del common law. Además, con el transcurso de los años se ha intensificado la práctica y las operaciones comerciales, de prospección y de explotación en el sector energético, dando lugar a numerosas sentencias dictadas por tribunales internacionales directamente relacionadas con esta importante actividad que involucra a muchos Estados, empresas y sociedades mercantiles completas. Para ejemplificar lo expuesto, se describen brevemente a continuación tres importantes sentencias que han sentado precedentes muy comentados.

Primero, está el caso Barcelona Traction Company, quizás uno de los más relevantes en la jurisprudencia internacional. Se refirió al trato que dio España a una compañía de electricidad canadiense en ese país, cuyos accionistas eran de nacionalidad belga. La decisión fue en el sentido de que, como norma de derecho internacional consuetudinario, lo que importa es la nacionalidad de la empresa, independientemente de la nacionalidad de sus accionistas. Segundo, está el caso Phillips Petroleum, el cual se remite a la demanda de indemnización por una compañía norteamericana por la expropiación de su coinversión realizada por las autoridades estatales de Irán. Concretamente se discutió y decidió sobre el valor de la indemnización y los criterios para formular dichos avalúos. Tercero, aparece el caso Anglo-Iranian Oil Co., que sometió el gobierno del Reino Unido a la CIJ, y el gobierno de Irán presentó una excepción basada en la falta de competencia. En 1933 se había concertado un acuerdo entre Irán y la Compañía, que en 1951 resultó nacionalizada por una ley estatal, dando lugar a la controversia. Irán sostenía que la Corte era 
competente sólo tratándose de tratados posteriores, en tanto que Reino Unido consideraba aplicables también los tratados anteriores al acto de expropiación. Finalmente, después de dictar medidas provisionales y de un rico debate, la Corte concluyó que carecía de competencia.

En suma, la jurisprudencia internacional en materia energética se conforma de los precedentes judiciales tanto de instancias internacionales cuya competencia es exclusiva para los Estados (CIJ o Corte Permanente de Arbitraje de La Haya) como de la emanada de cortes de arbitraje donde concurren las empresas para zanjar sus controversias. ${ }^{25} \mathrm{La}$ jurisprudencia constituye una fuente de derecho en la medida que interpreta el derecho existente a un caso determinado, y guía los trabajos del órgano judicial de la causa o arbitral competente en la resolución de casos futuros. Como ocurre en el DIPb, en el DIEn la jurisprudencia tiene una doble función: dilucidar el contenido del derecho y ser un medio para comprobar la existencia y la aplicación de las normas de jus gentium.

\section{F. La doctrina de los juristas y publicistas}

A nuestro modo de ver, en las actuales condiciones dinámicas de las relaciones internacionales, la doctrina puede ser considerada tanto como un recurso subsidiario como principal —independientemente del papel que le atribuye el precitado artículo 38 y la doctrina de él derivada- lo cual será determinado según cada caso y en atención a las circunstancias particulares, el contexto dominante, la familia jurídica de procedencia del juzgador y el razonamiento judicial que en cada situación se aplique. Y su importancia será mayor o menor, según sea jerarquizada por las cortes y tribunales internacionales o también en función de su capacidad de conectarse o de ser vinculada con otras fuentes del derecho internacional, por ejemplo con la costumbre y la jurisprudencia. ${ }^{26}$

25 Velázquez Elizarrarás, Juan Carlos, Geopolítica mundial de la energía fósil, México, SAHOP-DIGAASES-Pémex, 1981, p. 57. También véase: ONU, Resúmenes de los fallos, opiniones consultivas y providencias de la Corte Internacional de Justicia, Nueva York, 1992, pp. 33-35, 93-95, 104-107 y 118-121.

26 Cabe recordar que la Corte Permanente de Justicia Internacional llegó a emplear fórmulas que pueden asimilarse a la doctrina, por ejemplo, la de "opinión general" (en el asunto Wimbledon) o de "opinión cuasi universal" (en el asunto de las Colectividades Alemanas en Polonia). Y la misma CIJ se ha referido expresamente a la doctrina, cuando 
Ahora bien, conforme a la práctica prevaleciente, hablar de esta fuente obliga a enfatizar que a pesar de ser también considerada un medio auxiliar para la determinación de las reglas de derecho, históricamente ha sobresalido o disminuido su importancia en relación con el grado de desarrollo y de maduración de la ciencia jurídica, esto es, su importancia fue mucha en el derecho internacional general cuando los tratados y la costumbre eran escasos o indeterminados mientras que, actualmente, tiende a disminuir su impacto básicamente en la medida en que el derecho consuetudinario y el derecho convencional han ido evolucionando, consolidándose y sistematizándose. Este mismo axioma nos es útil para afirmar que en el DIEn, la doctrina de los publicistas es, en consecuencia, notoriamente relevante dadas las cualidades de novedad, insuficiencia, inexperiencia y desarrollo incipiente que tienen - entre otras fuentesla costumbre internacional energética y el derecho convencional energético.

De ahí que, deban apreciarse en su justa dimensión los análisis que, como el que intenta el presente artículo, pretenden contribuir al estudio, conocimiento y comprensión del derecho internacional tanto general, como del de su rama energética. La doctrina internacional en disciplinas del petróleo y de las fuentes alternas de energía, en estos precisos momentos del boom de 2008, puede facilitar en mucho la búsqueda de la norma jurídica, pero sin pretender - en un exceso de optimismo- que la simple opinión doctrinal tenga peso específico notorio ante el juez o el árbitro internacional o ante los nuevos paneles, comisiones o salas especializados en estas intrincadas materias. ${ }^{27}$

buscó una definición de la nacionalidad "según la práctica de los Estados, las decisiones arbitrales y judiciales, y las opiniones doctrinales" (sentencia relativa al asunto Nottebohm, del 6 de abril de 1955), y también en el dictamen sobre la "Constitución del Comité de Seguridad Marítima de la Organización Consultiva Marítima Intergubernamental”, al hablar de la jurisprudencia, y en la que se menciona expresa y claramente a la doctrina internacional, al lado de la jurisprudencia (aunque las dos, son consideradas finalmente como fuentes auxiliares).

27 Por parte de la Corte Permanente de Justicia Internacional, cabe recordar que ésta llegó a emplear fórmulas que pueden asimilarse a la doctrina, por ejemplo la de "opinión general" (en el asunto del Wimbledon) o de "opinión cuasi universal" (en el asunto de las Colectividades Alemanas en Polonia). Y la propia CIJ se ha referido expresamente a la doctrina, cuando buscó una definición de la nacionalidad "según la práctica de los Estados, las decisiones arbitrales y judiciales, y las opiniones doctrinales" (sentencia relativa al asunto Nottebohm, del 6 de abril de 1955), y también en el dictamen sobre la "Consti- 
Partiendo de la premisa que la doctrina es una fuente auxiliar del derecho que permite al juez comprobar la existencia de una norma de derecho con base en los trabajos realizados por académicos e investigadores reconocidos, la doctrina en el DIEn sigue la misma pauta y está constituida por los trabajos formulados por diversas agrupaciones especializadas en temas jurídicos y energéticos como son las siguientes: la International Bar Association (IBA), Section on Energy and Natural Resources, el American Petroleum Institute (API), la Internacional Law American Society (ILAS), la European Energy Commission (EEC), el Comité Jurídico Interamericano de la OEA, la Internacional Studies Association (ISA), la División Jurídica de la OLADE, por mencionar algunas de las más relevantes. También son de destacar los trabajos - verdaderas contribuciones doctrinales por su respaldo, profundidad y seriedad-, desarrollados por delegados nacionales del sector energético, enviados altamente especializados y técnicos permanentes asistentes o parte del estaff de organismos y conferencias internacionales de cobertura mundial, como son: la Conferencia Mundial de Energía, el Congreso Mundial del Gas, el Congreso Mundial del Petróleo, el Simposium de Energía en el Hemisferio Occidental y la Conferencia de Naciones Unidas sobre Fuentes de Energía Nuevas y Renovables. ${ }^{28}$

Como ocurrió en el pasado con el derecho internacional general, hoy el DIEn tiene un contenido impreciso y carece aún de certidumbre, por lo que es difícil determinarlo todavía, sus reglas son relativamente escasas y más o menos ineficaces por lo que - insistimos - la doctrina avanzada y profusa habrá de jugar un papel fundamental para su estructuración, desarrollo y difusión. Y esto resulta ser así porque el propio derecho internacional general, con siglos y siglos de evolución, continúa siendo, en muchos de sus aspectos, difícil de descubrir e interpretar. Por ello, las investigaciones de los estudiosos — principalmente de países productores y exportadores de petróleo y de otros recursos de energía - seguirán siendo muy útiles, no sólo para precisar el derecho positivo, sino también como guía para su desarrollo y como medio para llenar sus deficiencias. En este sentido, es necesario - al considerar las enseñanzas de los publi-

tución del Comité de Seguridad Marítima de la Organización Consultiva Marítima Intergubernamental", al hablar de la jurisprudencia, y en la que se menciona claramente a la doctrina internacional, al lado de la jurisprudencia.

28 Velázquez Elizarrarás, Juan Carlos, op. cit., nota 25, p. 60. 
cistas - no ignorar las opiniones que se originan o prevalecen en las diferentes regiones del mundo.

Asimismo, las opinio juris particulares y las decisiones de los jueces y árbitros internacionales también deben ser tomadas muy en cuenta. Ellas son de gran importancia, no sólo por la reputación y los cargos de sus autores, sino también en virtud de las condiciones en que producen sus criterios y observaciones, e incluso disidencias. A dichas opiniones corresponde una jerarquía intermedia entre las enseñanzas de los publicistas y las decisiones judiciales. Por su parte, la Comisión de Derecho Internacional (CDI) de la ONU — que constituye a la vez un cuerpo cuasilegislativo de publicistas que actúan con su respectiva capacidad personal y como institución internacional-, realiza también un trabajo doctrinario de extraordinaria calidad y de gran autoridad. Finalmente, son dignas de mencionarse las opiniones jurídicas y los estudios periciales preparados por las secretarías de las organizaciones internacionales en el desempeño de sus funciones, tal es el caso de agencias petroleras y energéticas como la OPEP, la OLADE, la AIE, la ARPEL, la Agencia Europea de Recursos Energéticos y el propio Parlamento Europeo.

\section{G. Las resoluciones de organismos internacionales soft law}

En la presente etapa histórica ya se perfila la actuación unilateral heterónoma creadora de normas jurídicas impuestas a los Estados soberanos, por el conducto de los organismos internacionales. Aunque, en esta transición aún es preponderante la voluntad soberana de los Estados, esta se combina con una clara tendencia al supranacionalismo, ${ }^{29}$ esto es, la sumisión del Estado a las decisiones adoptadas por instituciones de naturaleza y carácter supraestatal. En las dos últimas décadas del siglo XX comenzó a plantearse el valor jurídico que puede tener tal tipo de resoluciones. ${ }^{30}$

29 Véase mi artículo: "La organización internacional como subdisciplina, subsistema y paradigma de las relaciones internacionales contemporáneas: aproximaciones teóricas, interdisciplinariedad y reestructuración general”, Relaciones Internacionales, núm. 68, México, UNAM, Facultad de Ciencias Políticas y Sociales, octubre-diciembre, 1995, pp. 27-29.

30 En principio, estas entidades son creadas por los Estados mediante tratado constitutivo, en el que se establecen los órganos y las reglas de procedimiento y definen las competencias y funciones de la institución. En el ámbito de las competencias que les han sido atribuidas, y de acuerdo con los procedimientos establecidos, todas las organizacio- 
Ahora bien, como es común en las agencias energéticas del mundo actual, los términos empleados para calificar tales actos son muy distintos y heterogéneos, como también lo son los efectos jurídicos que conllevan. De hecho no existe una terminología unívoca para calificar los actos propios — unilaterales - referidos: se habla así de decisiones, declaraciones, reglamentos, notas, directivas, resoluciones, recomendaciones, estándares, prácticas, normas, despachos, anexos, entre los más comunes. No debe considerarse, por lo demás, que la denominación del acto permite la identificación de sus efectos jurídicos; incluso en el seno del sistema institucional un mismo término puede ser empleado para designar resoluciones de efectos jurídicos diferentes. ${ }^{31}$ Por tal razón, y sin entrar en discusión, consideramos la conveniencia de referirnos genéricamente a la palabra resoluciones.

Determinar los efectos jurídicos de las resoluciones y, por consiguiente, apreciar si, y hasta qué punto, son capaces de crear derechos y obligaciones para sus destinatarios, es una cuestión tan vigente y nodal como difícil de encuadrar en una teoría general. ${ }^{32} \mathrm{Al}$ ser tributarias de los rasgos esenciales de su subjetividad internacional, secundaria y funcional, la capacidad de las organizaciones para adoptar resoluciones jurídicamente vinculantes en el ámbito de sus competencias depende de la voluntad de los Estados miembros manifestada originariamente en su derecho fundacional u originario o tratado constitutivo y, consecuentemente, no todas disponen de la misma o de un mínimo común de capacidad. El acto de una organización puede materializarse desde una mera recomendación, cuyos destinatarios son invitados pero no obligados a seguir un determinado comportamiento, acción o abstención (por ejemplo, recomendaciones de la Asamblea General de la ONU, artículos 10 al

nes tienen la facultad de expresar, mediante determinados actos de sus órganos, una voluntad propia, jurídicamente distinta de la de los Estados miembros. Incluso, puede sostenerse que han sido creadas con la finalidad esencial de adoptar actos propios en el marco de la cooperación internacional institucionalizada para cuyo fortalecimiento fueron creadas.

31 Este es el caso, por ejemplo, de las recomendaciones de las instituciones comunitarias y de la Agencia Internacional de Energía de la OCDE, que en el ámbito de la CECA designan un acto obligatorio en cuanto al resultado (artículo 14 TCECA), mientras que en el sistema de la CE y de la CEEA reducen sus efectos al sentido etimológico del término, no siendo por tanto vinculantes (artículo 189 TCE y 161 TCEEA).

32 Remiro Brotóns, Antonio, Derecho internacional, Madrid, McGraw-Hill-Interamericana de España, 1998. 
14 de la Carta), hasta una norma directamente aplicable en los ordenamientos jurídicos de los Estados miembros, incluso, con primacía sobre sus leyes (por ejemplo, reglamentos de la OLADE, la OPEP o la OPAEP, reglas comunitarias, artículo $189 \mathrm{TCE}$, o las disposiciones reglamentarias de la ANSEA, del Mercosur o incluso del TLCAN, etcétera).

La capacidad decisoria de la institución intergubernamental podría ser establecida, por otro lado, como un poder implícito de aquélla, en atención a las necesidades del ejercicio de sus funciones y la realización de sus propósitos, y aun en virtud de su práctica establecida, esto es, las normas de derecho internacional consuetudinario a las que la actividad de la organización haya podido dar lugar, admitidas ya entre las reglas de la organización en Convenciones internacionales de particular actualidad y relevancia. ${ }^{33}$ Por consiguiente, debe enfatizarse que, como en los demás aspectos que afectan a su funcionamiento, la facultad de las organizaciones interestatales - $\mathrm{y}$, más concretamente, de sus diferentes órganos - para adoptar actos jurídicamente vinculantes ha de decidirse en el marco de cada organización.

En la medida en que tales facultades existan, las resoluciones, actos unilaterales de la institución, pueden considerarse fuente autónoma del derecho internacional, general y energético, si bien de carácter secundario o derivado, pues se encuentran jerárquicamente subordinadas a las normas de las que se originan: las reglas de la organización, en particular, las revisiones expresas o implícitas de su derecho originario, sus decisiones y resoluciones adoptadas de conformidad con ellas y su práctica establecida. Sin embargo, con frecuencia, la constitución no nos da la respuesta precisa. Es el caso de la Carta de la ONU que no da la definición jurídica de recomendación, a pesar de conferir a los órganos principales de la organización - excepto al secretario general - la facultad de hacer recomendaciones y regular cuidadosamente el ejercicio de dicha atribución. $^{34}$

33 Por ejemplo, los artículos 1.34 de la Convención de 1975 sobre la Representación de las Estados en sus Relaciones con las Organizaciones Internacionales, y 2.1.j de la Convención de 1986 sobre el Derecho de los Tratados entre Estados y Organizaciones Internacionales o entre Organizaciones Internacionales.

34 Este asunto ya ocupaba a varios doctrinarios desde mediados de los años cincuenta del siglo XX, por ejemplo véase: Virally, Michel, "La valeur juridique des recommandations des organisations internationales", 2 Annuaire Francais 69, París, 1956. 
Varios autores parecen temer - y por ello caen en contradicciones en sus textos al tocar este tema- a fijar una postura clara y precisa en cuanto a si las resoluciones de organismos internacionales son, o no, una fuente de derecho internacional; tal es el caso, por ejemplo, de Max Sorensen, Arthur Nussbaum o de Charles Rousseau. Es decir, por un lado confirman esta cualidad de las resoluciones y, por el otro, parecen tentados a negarla. Para nosotros, no queda lugar a dudas respecto de que sí constituyen una fuente, aunque, ciertamente, en evolución, no suficientemente estudiada por la doctrina y sujeta a puntos de vista distintos y hasta contrarios. Cada vez se muestran más numerosos los casos en que los actos de las instituciones internacionales crean obligaciones para los Estados, en especial cuando se trata de su contribución para la formación del derecho internacional consuetudinario.

También habría que considerar que en este tema, como en muchos otros del derecho internacional y del DIEn, siguen pesando mucho los criterios voluntaristas y positivistas para establecer el fundamento del orden jurídico internacional, en detrimento de los criterios iusnaturalistas, filosóficos o sociológicos. Es el caso de la obligatoriedad de cumplir lo pactado que, en la primer postura, se reduce estrictamente al principio res inter alios acta, o sea que el tratado sólo obliga a las partes. Aquí, si bien un Estado que no ha declarado que acepta una recomendación no queda obligado por ésta, sería justo preguntar si el principio de la buena fe permite a un Estado ignorar una recomendación que haya aprobado formalmente por voto afirmativo; aunque hasta el momento, no se ha establecido ninguna regla consuetudinaria a ese efecto. El que una resolución no sea obligatoria para los Estados, no obsta para que tenga fuerza vinculante en el orden interno de una institución.

Las resoluciones de la Asamblea General que transmiten instrucciones a los organismos subordinados a ésta — como el secretario general, el Ecosoc y el Consejo de Administración Fiduciaria - a la par que a los organismos contribuyentes que ella misma ha creado tienen, ${ }^{35}$ sin duda alguna, carácter obligatorio para sus destinatarios. En contraste, las recomendaciones hechas por ella al Consejo de Seguridad no son más que exhortaciones para tomar medidas, las cuales el Consejo no está obligado a aceptar, en virtud de su independencia de la Asamblea. Por consi-

35 Excepto los órganos judiciales, véase Opinión Consultiva sobre Awards of Administrative Tribunals [1954], Corte Internacional de Justicia, Rep. 47. 
guiente, las recomendaciones hechas por el órgano plenario de cualquier institución internacional a otros organismos subordinados - organismos especializados, como el OIEA-, serán obligatorias. En el DIEn observamos incluso, por ejemplo, que las resoluciones plenarias adoptadas por la OPEP son asumidas históricamente como obligatorias por los Estados árabes signatarios de otra institución, la OPAEP (recordemos las restricciones adoptadas en octubre de 1973 y que afectaron a todos los países industrializados).

A nuestro juicio resulta también inobjetable que el sistema de Naciones Unidas, a través de la Asamblea General, el Consejo de Seguridad, los organismos especializados y los de orden regional - en menor medida-, pueden funcionar como agentes de creación de normas jurídicas internacionales generales e inclusive específicas en materias de explotación y conservación de recursos naturales, entre los que se incluyen los energéticos; amén que los organismos político-técnicos como la OPEP, la OPAEP, la AIE y la OLADE lo hacen con la constitución de reglas y normas especiales en campos de su competencia estricta. No es que trate de un proceso legislativo directo o estatuario como afirman algunos publicistas, sino que ante un vacío legal, y ante la insuficiencia y la lentitud del mecanismo legislativo internacional — tanto el tradicional general como el que funciona en el sector energético-, este proceso de características políticas que algunos denominan "diplomacia parlamentaria", se ha venido consolidando en los últimos años y tiene en nuestra personal opinión, un considerable valor. ${ }^{36}$

36 Por ejemplo, para: a) refinar conceptos jurídicos generales y especiales, a través de su examen general; b) introducir con precisión el elemento de la opinio juris; c) clarificar problemas jurídicos del orden energético internacional y mundial; d) estimular la reglamentación de nuevas funciones internacionales energéticas; e) interpretar y aplicar la Carta de las Naciones Unidas o las cartas constitucionales de otros organismos, principalmente los de competencia energética y petrolera; f) revelar o introducir nuevos principios de derecho internacional de la energía; g) depurar y mejorar la labor que tienen a su cargo todos los cuerpos cuasi-legislativos de la escena jurídica mundial; $\mathrm{y}, \mathrm{h}$ ) elaborar el trabajo preparatorio de una auténtica legislación internacional energética propia del siglo XXI. Para ampliación de estas ideas, consúltese mi trabajo: "Reestructuración general del nuevo derecho internacional. perspectivas hacia el siglo XXI “, Temas selectos del nuevo derecho internacional, México, UNAM, Facultad de Ciencias Políticas y Sociales, 1994, pp. 29-31. 


\section{Regulación del mercado mundial del petróleo}

\section{A. Factores y comportamiento cíclico del mercado petrolero mundial}

En nuestra experiencia, los factores inexcusables del mercado petrolero mundial pueden revertirse y cambiar de posición y jugar un rol determinante e incierto, en cualquier momento histórico de las relaciones internacionales, ya que dependen de una serie de circunstancias y condiciones que muy pocos conocen y que, por ende, no logran predecir y ubicar con la precisión requerida en el juego de los Estados y las empresas en el escenario de la gran política energética. Esto significa que, en un sentido, tales agentes pueden provocar el abaratamiento de los hidrocarburos, pero en otro, como ahora, pueden ocasionar alzas tan inusitadas como irracionales y contrarias a toda lógica de mercado.

Estos factores $-\mathrm{o}$ fuerzas rectoras, como las denominan Ernest Mandel y Rikhardt Stajner- son las siguientes: la devaluación-revaluación del dólar (hoy el euro tiende a compartir con él una posición dominante en la comercialización mundial de los crudos), el agotamiento de las reservas, la especulación inducida, la disminución de la demanda, el aumento de la oferta o aun la sobreoferta, el comportamiento del mercado spot, libre, negro u ocasional, las ganancias de las grandes transnacionales, el uso eficiente de energía, la revaluación de los crudos ligeros y la devaluación de los crudos pesados, el aumento del ritmo de la acumulación de inventarios (reservas estratégicas, le llaman los Estados hegemónicos) y el incremento del costo de almacenamiento, y la recomposición orgánica del capital petrolero, entre otros más que han jugado un papel histórico sobresaliente. Cabe resaltar que, en cuanto a la regulación de su operación y la ordenación de su conducta, el DIEn sigue teniendo, como en el pasado, aún poca influencia y participación, siendo el ejemplo más revelador de dicha deficiencia el control relativo que tiene sobre el mercado negro de los hidrocarburos.

En cuanto concierne al comportamiento cíclico del mercado petrolero mundial, merece atención la anticipación que hizo apenas este 25 de junio de 2008 — ratificado a principios de agosto- el Departamento de Energía de Estados Unidos en el sentido de que la demanda de energéticos crecerá $50 \%$ durante los próximos veinte años, y el precio del barril de petróleo podría alcanzar 186 dólares en 2030. Entre tanto, el 
precio del barril continúa oscilando, luego de que los informes del gobierno estadounidense muestran que sus inventarios aumentaron porque los altos precios de los combustibles continuaron erosionando la demanda (el Texas bajó 2.45 dólares, a 134.55 el barril; mientras el Brent retrocedió 2.13 dólares, a 134.33; en tanto que la mezcla mexicana de crudo de exportación cerró en 116.36, un retroceso de 1.69 dólares, según reporte de la paraestatal Petróleos Mexicanos. ${ }^{37}$

La continua alza en los precios de los crudos de referencia se debe en parte al comportamiento del dólar, que ha venido cediendo terreno frente a las principales divisas en los mercados internacionales. En estos momentos hay inquietud en el mercado por las tensiones sobre la oferta de crudo y la espera de la decisión de política monetaria de la Reserva Federal de Estados Unidos, donde también pesa la tensión entre Irán e Israel. Se afirma que los precios tenderán a subir aún más por los rumores de un ataque sobre las instalaciones nucleares de Irán, en tanto que la OPEP manifestó que los precios no bajarán y que el organismo está prácticamente impedido para revertir la tendencia alcista, ya que se origina en maniobras complejas de redes de especuladores a nivel mundial.

Esta situación ha sido confirmada por el Comité del Senado de Seguridad Nacional y Asuntos Gubernamentales al exigir al gobierno de Estados Unidos intervenir con nuevas regulaciones para dominar la excesiva especulación en los mercados de materias primas, principalmente las de carácter estratégico incluyendo los hidrocarburos, que ha elevado artificiosamente los precios para los consumidores. Asimismo, la Comisión de Negociación de Futuros de Materias Primas ha sido acusada por muchos legisladores norteamericanos de haber sido demasiado complaciente con los especuladores mercantiles locales e internacionales. También en los

37 El 30 de julio de 2008 las agencias AFP, Reuters y DPA informaron que, después varias alzas sostenidas, el crudo bajó a un mínimo de seis semanas, en medio de preocupaciones sobre la caída de la demanda de energía y los crecientes problemas económicos en Estados Unidos. La mezcla mexicana de petróleo retrocedió 3.22 dólares, cerrando a 118.01 dólares por barril. El crudo ligero estadounidense cayó 3.09 dólares, para quedar a 127.95 por barril luego de haber caído hasta 125.63 dólares, su nivel más bajo desde fines de mayo. El Brent de Londres perdió 3.06 dólares, ubicándose en 129.55 dólares. Para estas fechas, el petróleo se halla 30 por ciento por encima de su nivel del inicio de 2008, y seis veces por sobre su precio de 2002, "en una escalada impulsada por el sorprendente crecimiento de China, India y otras economías asiáticas en vías de desarrollo", La Jornada, Sección Economía, p. 30. 
medios europeos, asiáticos y latinoamericanos se han hecho denuncias similares, al igual que al interior de las conferencias de organismos de integración regional como la Unión Africana y la ANSEA.

Por ello, advertimos que esta situación coyuntural de especulación mundial no debe ser tomada, por su naturaleza incierta y su intención desestabilizadora, como argumento central para promover en México una reforma gubernamental sectorial sin los debidos fundamentos, carente de planificación y con alcances cortos y que, por su carácter también sesgado y coyuntural, seguramente no podrá conducir a mejorar las condiciones sociales, económicas y políticas prevalecientes en el país.

\section{B. Características y referentes básicos del comercio petrolero}

El petróleo crudo es una mezcla de hidrocarburos compuesta de pequeñas cantidades de azufre, oxígeno, nitrógeno y otros metales como el vanadio, níquel, sodio y demás considerados como impurezas que afectan su calidad y por ende su cotización. Por sí solo, el crudo tiene poca utilidad para las actividades industriales, requiere de un proceso de refinación mediante el cual es transformado para su utilización en la fabricación de productos intermedios que a su vez constituyen la materia prima para la obtención de otros productos industriales como los combustibles, aceites, lubricantes, asfaltos y una gran variedad de productos petroquímicos como el plástico, los fertilizantes, los catalizadores y los solventes.

La industria mundial de hidrocarburos clasifica al petróleo con base a su densidad relativa o a su gravedad especifica en grados API ${ }^{38}$ parámetro empleado por el American Petroleum Institute para calificar la calidad del crudo. De acuerdo a la escala API, entre más ligero es un petróleo, mayor es su gravedad API y cuanto más pesado sea, menor su gravedad. Mientras más ligero sea un petróleo crudo mayor será su calidad y precio de cotización en el mercado internacional. ${ }^{39}$

El mercado internacional del petróleo se encuentra constituido por dos actores fundamentales: los productores-exportadores y los consumi-

38 Gradiente establecido por el American Petroleum Institute (API), y reconocido como estándar mundial.

39 México, por ejemplo, produce tres tipos de crudo, a saber: Istmo, ligero con densidad de $33.6^{\circ}$ API y $13 \%$ de azufre; Maya, pesado con densidad de $22^{\circ}$ API y 3.3 . de azufre, y, Olmeca, superligero con densidad de $39.3^{\circ}$ API y $0.8 \%$ de azufre. Instituto Mexicano del Petróleo (IMP). www.imp.mx. 
dores. En el primer caso, encontramos empresas privadas y estatales dedicadas a la extracción y exportación de petróleo crudo y algunas dedicadas a su refinación. En el segundo caso, tenemos a los Estados y a los intermediarios especializados, es decir, a las compañías refinadoras, especuladores, administradores de riesgo y las propias empresas petroleras. Cabe mencionar que algunas empresas tienen participación, a través de subsidiarias, tanto en la oferta como en la demanda del crudo.

Las principales empresas ofertantes del petróleo en el mundo son la Saudi-Aramco de Arabia Saudita, NIOC de Irán, KPC de Kuwait, INOR de Irak, ADNOC de los Emiratos Árabes Unidos, NOC de Libia, PNC de Nigeria, PDVSA de Venezuela, Pémex de México y el grupo de las denominadas siete hermanas: Exxon, Gulf, Texaco, Mobil, Standard Oil de California, British Petroleum y Royal Dutch Shell.

El mercado internacional establece tres modalidades de fijación de precios para el petróleo crudo, a saber: 1) el precio de cesión; 2) el precio de transferencia, y 3) el precio de referencia.

1) Precio de cesión. Es un precio fijado y pagado efectivamente con base en el valor comercial del crudo por dos agentes económicos sin relación alguna.

2) Precio de transferencia. Es un precio fijado sin tener en cuenta el valor comercial del crudo, a través del cual un agente económico cede ciertas cantidades de petróleo a otro agente económico con el cual mantiene algún tipo de asociación. Dicha transacción no constituye una práctica desleal al comercio sancionada por el derecho internacional —dumping o subvención, por ejemplo - ya que existe un vínculo de asociación entre las partes involucradas.

3) Precio de referencia. Es un precio convenido entre un Estado y las empresas productoras de petróleo. El precio fijado tiene que ser igual al que cualquier otro comprador podría adquirir el mismo crudo. En realidad, el precio de referencia es fijado de manera ficticia por parte del oferente. Actualmente, la cotización de los diferentes crudos del mundo se realiza con base al precio de petróleos de referencia cuya alta calidad sirve de base para fijar el valor de los petróleos restantes. Este sistema funciona sobre la base de diferenciales (primas o descuentos) respecto de un crudo determinado o mediante fórmulas que integran una canasta de crudos.

Los principales crudos de referencia que sirven de indicadores para la fijación de los precios internacionales del petróleo son el West Texas Intermediate (WTI), el Brent y el Dubai, en torno a los cuales se ha desa- 
rrollado una gran infraestructura de transporte, almacenamiento y servicios, así como notorias facilidades de información, regulaciones y modalidades de contratos, que permiten que el comercio se mantenga regulado y realice con eficiencia y certidumbre; además, estos crudos se negocian bajo modalidades de entrega física, contratos adelantados, futuros y otros derivados, que facilitan la administración de riesgos.

No obstante el reducido volumen físico de producción de petróleos como el WTI y el Brent, el mercado internacional les ha otorgado una función de referencia de valor para la cotización del precio del resto de los crudos, ya que ambos petróleos reúnen requisitos de alta calidad tanto en grados API como en bajo contenido de azufre.

\section{a. El Brent}

El petróleo Brent es de alta calidad debido a que es ligero y de bajo contenido de azufre. Es el crudo de referencia para el mercado europeo, pero también lo es para el $65 \%$ de los distintos tipos de crudo mundial, cuyos precios son fijados como una prima o descuento con respecto al valor del Brent. Los contratos a futuro y las opciones Brent cotizan en el International Petroleum Exchange (IPE) de Londres. En torno a dicho crudo se ha estructurado todo un sistema financiero de comercialización del petróleo bajo tres modalidades distintas: a) el dated Brent, b) el 15 day Brent, y c) los contratos por referencias o CFD. 40

a) Dated Brent. Es el contrato de petróleo del mercado físico (mercado spot). Bajo esta modalidad se intercambian barriles reales de crudo de forma inmediata y a un precio fijado con base en estimaciones elaboradas por varias empresas tras averiguar las posiciones de oferta y compra a los intermediarios y petroleras que intercambian barriles. Los cargamentos de dated Brent son para carga inmediata, habitualmente a quince días vista o lo menos tarde posible con respecto a esos quince días, teniendo en cuenta los días no hábiles para la contratación. Hoy en día, debido al declive en la producción de este crudo, los contratos dated Brent se refieren a los precios de una mezcla o canasta de tres crudos producidos en el mar del Norte, a saber: el Brent, el Forties y el Oseberg.

40 Véase Velázquez Elizarrarás, Juan Carlos, “Los acuerdos Christopher-Castañeda sobre la compra-venta de gas natural", Revista Cardinal, México, UNAM, Facultad de Derecho, núm. 62, 1982, pp. 13-19. 
b) 15 day Brent. A través de este contrato adelantado, el vendedor y el comprador se comprometen a realizar una transacción, en la que el comprador cuenta con un plazo de 15 días para avisar sobre las características y requerimientos del embarque de un volumen determinado de barriles de crudo (cada barril contiene 199 litros).

c) Contratos por referencias o CFD. En este tipo de contrato confluyen las dos modalidades anteriores y permite a las partes cubrir posible riesgos provocados por futuras fluctuaciones en los precios internacionales del petróleo. A través de esta modalidad el comprador adquiere una determinada cantidad de barriles de crudo a un precio dated Brent con una fecha de entrega 15 day Brent. El petróleo se vende al precio del día, pero con una fecha de entrega a futuro.

\section{$b$. El West Texas Intermediate}

Es el petróleo de referencia para el mercado de Estados Unidos y para todos los crudos de exportación de Sudamérica, y cotiza en la New York Mercantile Exchange (NYMEX), en Nueva York. Su producción es para el consumo local, pero se trata de un crudo de muy alta calidad, por ello suele cotizarse entre dos y cuatro dólares por encima del Brent. Sus contratos de futuro cuentan con el mayor nivel de liquidez y contratación de todos los crudos mundiales, con operaciones que alcanzan los ciento cincuenta millones de barriles. Al vencimiento del contrato de futuros, el comprador puede exigir la entrega física del producto o la compensación en metálico.

\section{c. El Dubai}

Es el petróleo de referencia para el crudo pesado y azufroso en Asia, y sobre su valor se fijan los precios de otros crudos de la zona que no cotizan en el mercado, así como los precios de los petróleos pesados provenientes de Arabia Saudita, Irak, y Kuwait. Este crudo es de baja calidad; es pesado $28^{\circ}-31^{\circ}$ API y de alto contenido en azufre. Su importancia se debe a que es el principal petróleo de exportación hacia las economías emergentes del sureste asiático. El Dubai cotiza en la Singapur International Monetary Exchange (Simex), en el mercado de materias primas de Singapur, y en la New York Mercantile Exchange (Nymex). 
Hasta principios de la década de los años ochenta, el precio de todos los crudos del mundo se fijaba como un diferencial con respecto al petróleo Árabe Ligero (Arabian Light) producido en el super yacimiento Ghawar, en Arabia Saudita. El Árabe Ligero es un crudo de mediana calidad, pero su producción es enorme, en la actualidad se producen más de cinco millones de barriles al día. Obviamente, debido a la abundancia y calidad media de este crudo, los precios internacionales, en concordancia con las leyes de la oferta y la demanda, comenzaron a fijarse con base en petróleos de mayor calidad y producción reducida. Actualmente, el precio del Árabe Ligero es fijado por la OPEP y difundido por la OPAEP.

\section{d. La cesta OPEP}

La Organización de Países Exportadores de Petróleo (OPEP) fija el precio para una canasta de siete crudos de mediana calidad entre los que se encuentran el Saharan Blend (Argelia), el Bonny Ligero (Nigeria), el Árabe Ligero (Arabia Saudita), el Dubai (Emiratos Árabes Unidos), el Tía Juana Ligero (Venezuela), y el Istmo (México). La cesta OPEP se compone de crudos de mediana y baja calidad cuyo precio constituye una media aritmética del valor de dichos crudos que oscila entre cuatro y cinco dólares por debajo del precio del WTI. La cesta OPEP comenzó a cotizar el 1 de enero de 1987 y su precio es anunciado por la OPEP un día después de que se han dado a conocer los precios de los demás crudos del mundo.

\section{Los contratos internacionales de comercialización del petróleo}

La comercialización internacional de petróleo y demás hidrocarburos se realiza a través de contratos internacionales entre empresas públicas y privadas transnacionales o bien entre Estados y empresas transnacionales. En este sentido, el contrato de petróleo es de carácter internacional. El contrato internacional puede ser definido como el "instrumento de concertación internacional que, por definición, está vinculado con varios sistemas jurídicos a la vez. Dicha vinculación resulta de la presencia en él de elementos objetivos y subjetivos cuyo origen o desarrollo se ubica en el ámbito jurídico de diferentes Estados, como son, en general, la voluntad de las partes, su nacionalidad, su domicilio, el lugar de celebra- 
ción del contrato y el lugar de su ejecución" ${ }^{41}$ En este sentido, el contrato de hidrocarburos — gas y petróleo básicamente- es de carácter internacional cuando existe por lo menos un elemento de extranjería. ${ }^{42}$

Como sostiene Rogelio López Velarde, si se trata de un determinado contrato internacional de compraventa de petróleo,

dicho acuerdo de voluntades podría estar sujeto a la Convención de Viena sobre la Compraventa Internacional de Mercaderías. La trascendencia de la Convención de Viena es tal, no sólo porque regula lo relativo a la formación y perfeccionamiento de la compraventa mercantil internacional, sino porque también regula los derechos y obligaciones de las partes. El ámbito personal de validez de dicho tratado no distingue la naturaleza jurídica del vendedor o el comprador. ${ }^{43}$

Actualmente existe gran variedad de modalidades a través de las cuales se comercializa el petróleo a nivel mundial. En términos contractuales reconocidos del DIEn, las operaciones de compra-venta de crudo se negocian bajo modalidades de entrega física, contratos adelantados o futuros, contratos de opciones, swaps, y contratos riesgo. A continuación pasaremos a revisar de manera sucinta cada una de estas modalidades de contratación internacional.

\section{a. Entrega física o mercado spot}

Es una transacción inmediata que no trasciende en el tiempo a través de la cual se acuerda la operación de compraventa de una determinada cantidad de petróleo cuyo precio corresponde al valor del crudo en ese momento. La entrega de producto y la liquidación del mismo son de forma inmediata y en efectivo.

Las transacciones spot son la forma más común en que se comercializa el petróleo en nuestros días, ya que son operaciones rápidas sin mayores formalismos legales y se encuentran exentas de las fluctuaciones

41 Velázquez Elizarrarás, Juan Carlos, op. cit., nota 2, p. 349.

42 Péreznieto Castro, Leonel y Silva Silva, Jorge Alberto, Derecho internacional privado. Parte especial, México, Oxford University Press-Harla, 2000 (véase la parte de contratos internacionales).

43 López Velarde, Rogelio, “Contratos internacionales de petróleo y gas. Algunas consideraciones jurídicas", Regulación del sector energético, México, Secretaría de Energía-UNAM, Instituto de Investigaciones Jurídicas, 1997, p. 544. 
de los precios internacionales del petróleo en el futuro. Sin embargo, el mercado abierto es bastante susceptible a los acontecimientos políticos, económicos, sociales y hasta climatológicos que afectan diariamente al mundo. Es así, que el valor actual de crudo puede incrementarse mañana o caer de manera precipitada.

El mercado spot (también denominado libre, ocasional, o incluso "negro") juega un papel muy importante en la comercialización del crudo, ya que es el medio idóneo para que las empresas petroleras vendan sus excedentes, es decir, el volumen de las transacciones spot refleja la oferta y demanda de petróleo a nivel mundial. A mayor demanda de crudo en el mercado spot, los ofertantes deben aumentar su producción; mientras que, una menor demanda, significa un excedente en la producción de crudo.

\section{b. Contratos futuros y contratos adelantados (forwards)}

A través de este tipo de contratos las partes se obligan a comprar o vender a futuro una cantidad de petróleo de una calidad determinada y un precio previamente establecido. La liquidación de estos contratos puede hacerse en especie o en efectivo.

Existen diferencias básicas entre los contratos adelantados y los futuros. Los primeros son esencialmente negociables en cuanto a precio, plazo, calidad, cantidad, lugar de entrega del producto y forma de liquidación. Los segundos, por su lado, operan en ambientes organizados donde existen reglas especificas y menores márgenes de negociación con respecto a precios, plazos, cantidades, calidades, lugares de entrega y formas de liquidación ya que buscan cubrir los riegos inherentes a la fluctuación de los precios internacionales del petróleo.

\section{c. Contratos de opciones}

Mediante este contrato una de las partes adquiere un derecho para comprar o vender crudo a un precio determinado denominado precio de ejercicio, en una fecha o periodo establecidos, por el pago de una prima (precio de la opción); mientras que la parte que emite o vende la opción se obliga a comprar o vender crudo de acuerdo a los términos establecidos en el contrato. Así, el adquirente tiene un derecho que puede o no ejercer, mientras que el emisor de la opción tiene una obligación con res- 
pecto a la parte adquirente del derecho de opción. La liquidación de la opción, en caso de que sea ejercida por el adquirente, puede hacerse en efectivo o en especie según lo acordado en el contrato.

\section{d. Swaps}

Es un tipo de contrato en el que las partes se comprometen a intercambiar una determinada cantidad de bienes (en este caso petróleo) durante un tiempo y precio previamente establecido. La principal características de este contrato reside en que tanto el comprador como el vendedor asumen riesgos relacionados con las fluctuaciones en los precios y producción del crudo. De esta manera, el precio fijado por adelantado puede disminuir durante la ejecución del contrato dando como resultado una pérdida para el comprador o viceversa. Sin embargo, al final de los periodos de entrega acordados, se compara el precio de mercado con el precio previamente establecido y se compensan los saldos netos de pérdida o de ganancia. ${ }^{44}$

\section{e. Contratos riesgo}

Es una modalidad contractual que pueden adoptar los contratos de exploración, localización, perforación y explotación de recursos naturales que se encuentran en el subsuelo de un determinado país. Consiste en asignar la carga y responsabilidad de las inversiones, así como todos o partes de los riesgos del negocio de explotación petrolera, a la empresa contratista que ha accedido prestar el citado servicio. ${ }^{45}$ De acuerdo con el éxito que se tenga en la exploración y producción del hidrocarburo, dependerá la posibilidad de que este contratista pueda recuperar sus inversiones y demás costos, más un premio que se le conoce como risk fee, es decir, una prima que equivale a un porcentaje por parte de lo extraído, la cual puede ser remunerada a través del pago equivalente en divisas de dicho porcentaje o la entrega de dicho porcentaje del hidrocarburo extraído como pago en especie (royalty in kind). En algunos casos, inclusive, se

44 Véase la tesis, González Álvarez, Lorena, El derecho de la contratación financiera internacional y su aplicación a los contratos Swaps en México, México, UNAM, Facultad de Ciencias Políticas y Sociales, 2007, p. 185. Ahí también se analizan otras variedades contractuales aplicables al caso petrolero.

45 Parra Rodríguez, Carmen, El nuevo derecho internacional de los contratos, Barcelona, UEC-Bosch, 2002, pp. 37-62. 
otorgan los derechos reales al contratista respecto al porcentaje estipulado y la producción de petróleo obtenida.

\section{d. El arbitraje comercial internacional en materia de hidrocarburos}

Conforme al DIEn, es una práctica generalizada que los contratos internacionales de petróleo incluyan una cláusula compromisoria o arbitral donde las partes, con base en la autonomía de la voluntad, establezcan el foro (lugar, país, corte o tribunal) y el derecho aplicable a la solución de controversias surgidas del incumplimiento de un contrato.

El acelerado crecimiento del comercio internacional en todas sus áreas - como la energética - ha puesto de manifiesto la necesidad de contar con mecanismos de solución de controversias que actúen de manera rápida, den una respuesta justa, y estén alejados de la competencia de los tribunales nacionales a fin de evitar una posible parcialidad de los mismos, así como de acudir a los métodos conflictuales o particulares del conflicto de leyes del DIPr, para regular de manera eficiente este importante aspecto del tráfico jurídico internacional. Así, el instrumento arbitral se presenta en la actualidad como la principal vía a la que recurren las empresas para dirimir sus diferencias comerciales en un marco de legalidad y con base en criterios jurídicos uniformes.

En México, el artículo 14 de la Ley Orgánica de Petróleos Mexicanos y Organismos Subsidiarios, establece: "tratándose de actos jurídicos de carácter internacional, Petróleos Mexicanos o sus Organismos Subsidiarios podrán convenir la aplicación de derecho extranjero, la jurisdicción de tribunales extranjeros en asuntos mercantiles y celebrar acuerdos arbitrales cuando así convenga al mejor cumplimiento de su objeto". No es poco común que Pemex se someta al derecho extranjero o acepte estipular una cláusula de prórroga de competencia de tribunales extranjeros, con relación a cierto tipo de contratos internacionales que regularmente celebra la paraestatal. Tal es el caso de los contratos internacionales de crédito, contratos marítimos y cierto tipo de contratos de servicios.

\section{REFLEXIONES FINALES}

A medida que se ha incrementado la importancia del petróleo como principal fuente de energía en el mundo - el cuarto factor de la produc- 
ción-, revolucionando la dinámica política y las negociaciones diplomático-estratégicas para su comercialización, los productores-exportadores y los compradores de crudo se han visto en la necesidad de crear, reconocer y aplicar un cuerpo jurídico uniforme que regule las transacciones del principal recurso energético del planeta.

En una primera época, esta actividad estuvo ordenada por los usos y costumbres aplicables a la comercialización de materias primas o productos básicos, es decir, la fuente primigenia reguladora de las actividades de compra y venta internacional de hidrocarburos fue lo que los iusprivatistas denominan como lex mercatoria. En este periodo, la participación de los países productores de petróleo en la estructuración del mercado internacional y en la fijación de precios fue mínima, debido al control monopólico ejercido por las naciones desarrolladas y sus grandes sociedades mercantiles o empresas transnacionales.

En una segunda época, observamos que la comercialización internacional del petróleo está estrechamente vinculada con el derecho internacional de la energía (DIEn); una rama del derecho internacional general, o cuerpo jurídico particular, que consagró el derecho soberano de los Estados a la explotación de sus recursos naturales. A raíz del proceso de descolonización producido en la década de los sesenta del siglo pasado bajo los auspicios de la ONU, las naciones que hasta ese entonces habían sido colonias tomaron el control sobre la explotación libre de sus recursos naturales a través de expropiaciones y nacionalizaciones.

En este contexto, los nuevos Estados independientes asumieron un papel activo en el mercadeo internacional del oro negro, hasta llegar, en la actualidad, a constituir y consagrar el contrato internacional bajo distintas modalidades de compraventa, como el principal mecanismo de comercialización del vital recurso. De esta suerte, estos instrumentos especiales, junto con los tratados interestatales en el rubro, están regulados por el derecho internacional público en cuanto se refieren a actos de comercio de materias primas (Convención de Viena de 1980), y también por el derecho internacional privado por lo que concierne a la contratación internacional, el conflicto de leyes y la solución de controversias mercantiles.

Respecto de las fuentes del DIEn, concluimos que son esencialmente fuentes de derecho internacional público y no difieren mucho de éstas, presentando empero, algunas particularidades, como es el hecho de que su objeto de regulación lo constituyen una serie de sectores de la activi- 
dad económica y política que han cobrado existencia propia y exigen un marco normativo particular; tal es el caso concreto del sector energético y del mercado mundial del petróleo, que no sólo destacan por su trascendencia geoeconómica y geopolítica, sino por el impacto que tienen en el diseño e implementación de políticas nacionales. Asimismo, hoy resalta el juego de posturas que han asumido los Estados en estas materias y que ha sido fundamental para el desarrollo de varios institutos que forman parte del $\mathrm{DIPb}$, por ejemplo la nacionalización-expropiación, la soberanía estatal sobre los recursos naturales, los embargos comerciales, las sanciones, y los nuevos métodos de adquisición de soberanía territorial, entre otros más.

Finalmente, sobre el mercado mundial del petróleo, se puede resumir que está regido en buena medida por factores inexcusables cuyo comportamiento depende de una serie de circunstancias y condiciones poco conocidas, que encaminan el rol de los Estados y las empresas en el proscenio de la gran política energética. Esto significa que, en un sentido, tales agentes pueden provocar el abaratamiento de los hidrocarburos, pero en otro, como ahora al final de la primera década del siglo XXI, ocasionar alzas tan inusitadas como irracionales y contrarias a toda lógica económica y comercial.

En este escenario dinámico y complejo, es válido asegurar que, en cuanto a la regulación de su operación y la ordenación de su comportamiento, el DIEn sigue teniendo, como en el pasado, aún poca influencia y participación en el gran comercio internacional, siendo el ejemplo más revelador de dicha insuficiencia el relativo control que aún ejerce sobre el mercado negro mundial de los hidrocarburos. 